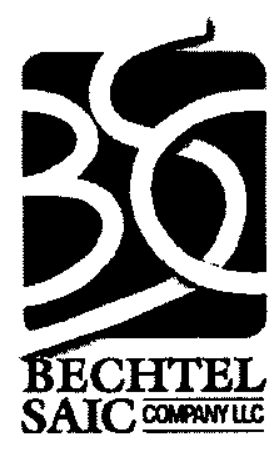

QA: QA

TDR-WHS-MD-000004 REV 01

August 2004

\title{
Preclosure Seismic Design Methodology for a Geologic Repository at Yucca Mountain
}

Prepared for:

U.S. Department of Energy

Office of Civilian Radioactive Waste Management

Office of Repository Development

1551 Hillshire Drive

Las Vegas, NV 89134-6321

Prepared by:

Bechtel SAIC Company, LLC

1180 Town Center Drive

Las Vegas, Nevada 89144

Under Contract Number

DE-AC28-01RW12101 


\section{DISCLAIMER}

This report was prepared as an account of work sponsored by an agency of the United States Government. Neither the United States Government nor any agency thereof, nor any of their employees, nor any of their contractors, subcontractors or their employees, makes any warranty, express or implied, or assumes any legal liability or responsibility for the accuracy, completeness, or any third party's use or the results of such use of any information, apparatus, product, or process disclosed, or represents that its use would not infringe privately owned rights. Reference herein to any specific commercial product, process, or service by trade name, trademark, manufacturer, or otherwise, does not necessarily constitute or imply its endorsement, recommendation, or favoring by the United States Government or any agency thereof or its contractors or subcontractors. The views and opinions of authors expressed herein do not necessarily state or reflect those of the United States Government or any agency thereof. 
Preclosure Seismic Design Methodology for a Geological Repository at Yucca Mountain

Originator:
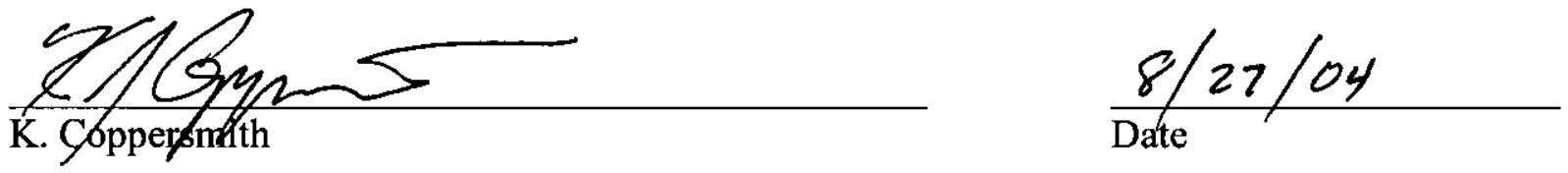

Checker:

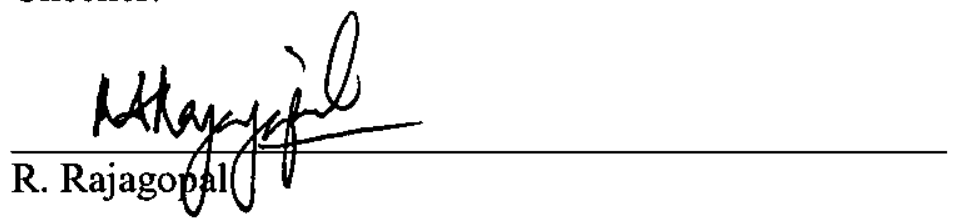

$\frac{8 / 27 / 04}{\text { Date }}$

Quality Engineer Representative:

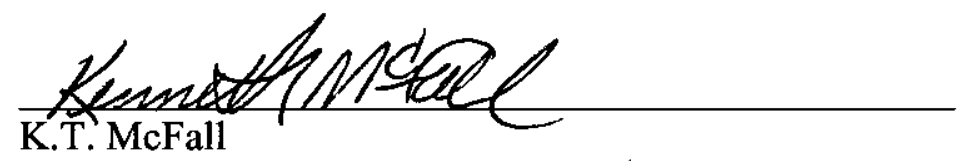

$\frac{8 / 27 / 04}{\text { Date }}$

Responsible Manager:

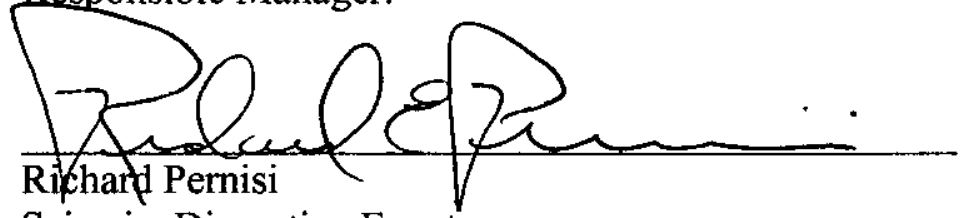

$\frac{8 / 27 / 04}{\text { Date }}$

Seismic, Disruptive Events 


\section{CHANGE HISTORY}

\begin{tabular}{|c|c|c|c|}
\hline $\begin{array}{l}\text { Revision } \\
\text { Number }\end{array}$ & $\begin{array}{l}\text { Interim } \\
\text { Change No. }\end{array}$ & $\begin{array}{l}\text { Effective } \\
\text { Date }\end{array}$ & Description of Change \\
\hline 00 & & 01/21/04 & Initial issue \\
\hline 01 & & & $\begin{array}{l}\text { Minor revisions to clarify: relationship to preclosure } \\
\text { safety analysis; seismic design will apply to SSCs } \\
\text { ITS with seismically initiated event sequences; } \\
\text { beyond-design basis analyses will be performed for } \\
\text { DBGM-2 SSCs ITS; and further define relationship } \\
\text { of Type I faults to design bases. Miscellaneous } \\
\text { editorial changes for internal consistency. }\end{array}$ \\
\hline
\end{tabular}




\section{CONTENTS}

ACRONYMS AND ABBREVIATIONS

Page

ix

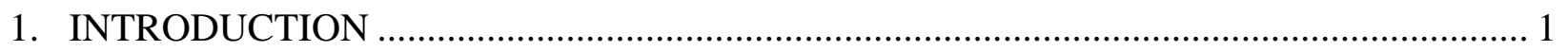

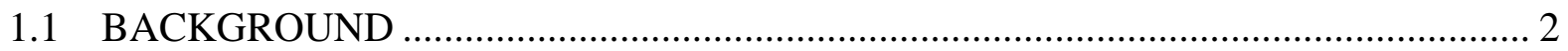

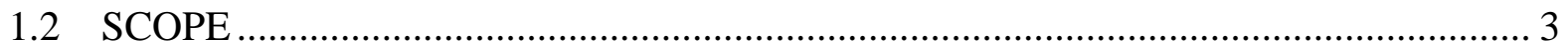

1.2.1 Relation to Preclosure Safety Analysis........................................................ 4

1.2.2 Relation To Preclosure Repository Design And Postclosure Performance

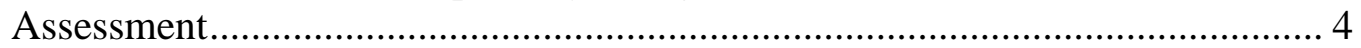

1.3 ORGANIZATION OF THIS REPORT ................................................................ 5

2. REGULATORY FRAMEWORK ............................................................................ 5

2.110 CFR PART 63 "DISPOSAL OF HIGH-LEVEL RADIOACTIVE WASTES IN A PROPOSED GEOLOGIC REPOSITORY AT YUCCA MOUNTAIN, NEVADA” .... 6

2.1.1 Preclosure Performance Objectives .............................................................. 7

2.1.2 Preclosure Safety Analysis ...................................................................... 8

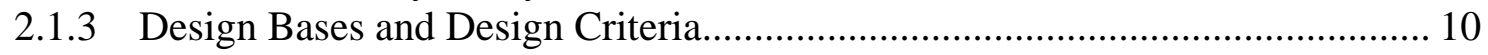

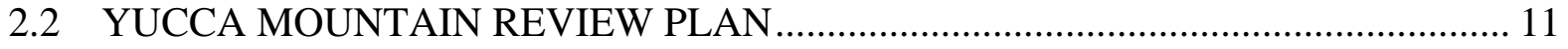

2.3 SEISMIC DESIGN OF NUCLEAR POWER PLANTS AND OTHER NUCLEAR

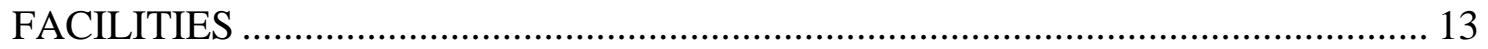

2.4 NUREG-0800, STANDARD REVIEW PLAN .................................................... 16

3. DESIGN BASIS GROUND MOTIONS AND DESIGN PROCEDURES ......................... 16

3.1 DESIGN BASIS GROUND MOTIONS FOR SSCS IMPORTANT TO SAFETY ..... 17

3.1.1 Design Basis Ground Motion Levels ........................................................... 17

3.2 DESIGN PROCEDURES AND ACCEPTANCE CRITERIA: NUREG-0800 ........... 20

3.3 SEISMIC MARGIN EVALUATION.................................................................... 22

3.3.1 Beyond-Design Basis Ground Motions Analysis ........................................ 22

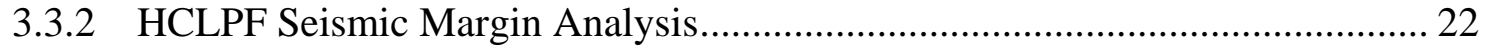

3.4 COMPARISON WITH OTHER SEISMIC DESIGN BASES ................................. 23

4. MITIGATION OF FAULT DISPLACEMENT HAZARDS ........................................... 26

4.1 CRITERIA FOR FAULT AVOIDANCE............................................................. 26

4.1.1 Implementation of NRC Staff Technical Position on Consideration of Fault

Displacement Hazards in Geologic Repository Design................................... 27

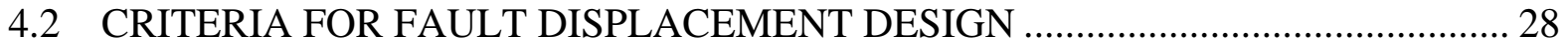

4.2.1 Determination of Design Basis Fault Displacements .................................... 28

4.2.2 Acceptance Criteria for Fault Displacement Design ..................................... 28

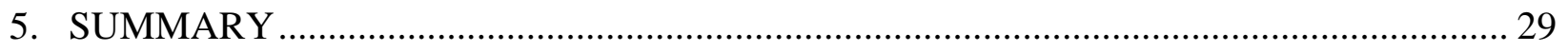

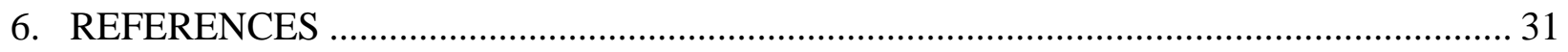

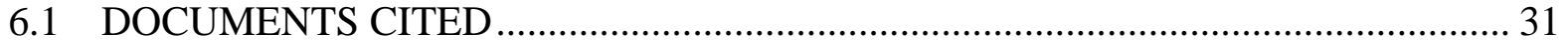

6.2 CODES, STANDARDS, REGULATIONS, AND PROCEDURES .......................... 34 


\section{CONTENTS (Continued)}

Page

APPENDIX A - Beyond-Design Basis Earthquake Ground Motions Analysis ........................ A-1 APPENDIX B - Development of HCLPF Seismic Margin Estimates ....................................... 


\section{TABLES}

1. Bases for Assigning Design Basis Ground Motion Levels to SSCs ITS ........................ 18

2. Comparison of Seismic Design Bases, Risk Reduction Ratios, and Failure

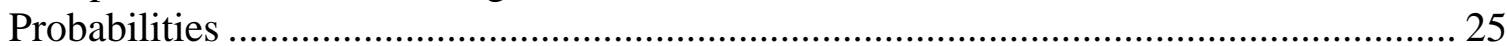




\section{INTENTIONALLY LEFT BLANK}




\section{ACRONYMS AND ABBREVIATIONS}

\begin{tabular}{|c|c|}
\hline BDBGM & beyond-design basis ground motion \\
\hline BSC & Bechtel SAIC Company, LLC \\
\hline CDFM & Conservative-Deterministic-Failure-Margin \\
\hline CFR & Code of Federal Regulations \\
\hline DBFD-1, 2 & Design Basis Fault Displacement -1, -2 \\
\hline DBGM-1,-2 & Design Basis Ground Motions -1, -2 \\
\hline DOE & U.S. Department of Energy \\
\hline HCLPF & high confidence of low probability of failure \\
\hline IBC & International Building Code \\
\hline ISA & Integrated Safety Analysis \\
\hline ITS & important to safety \\
\hline LA & License Application \\
\hline MAPE & mean annual probability of exceedance \\
\hline NPP & nuclear power plant \\
\hline NRC & U.S. Nuclear Regulatory Commission \\
\hline OBE & operating basis earthquake \\
\hline PCSA & preclosure safety analysis \\
\hline PSA & preclosure safety analysis (usage in 66 FR 55732, 55741) \\
\hline PSHA & probabilistic seismic hazard analysis \\
\hline $\mathrm{R}_{\mathrm{R}}$ & risk reduction ratio \\
\hline SSCs & structures, systems, and components \\
\hline SSE & safe shutdown earthquake \\
\hline STR\#1 & $\begin{array}{l}\text { Seismic Topical Report \#1, Methodology to Assess Fault Displacement and } \\
\text { Vibratory Ground Motion Hazards at Yucca Mountain (YMP } 1997 \\
\text { [DIRS 100522]) }\end{array}$ \\
\hline STR\#2 & Seismic Topical Report \#2, which is this report \\
\hline TEDE & total effective dose equivalent \\
\hline TSPA-LA & total system performance assessment for the License Application \\
\hline YMP & Uucca Mountain Site Characterization Project \\
\hline
\end{tabular}




\section{INTENTIONALLY LEFT BLANK}




\section{INTRODUCTION}

This topical report describes the methodology and criteria that the U.S. Department of Energy (DOE) intends to use for preclosure seismic design of structures, systems, and components (SSCs) that are important to safety (ITS) in the geologic repository operations area. 10 Code of Federal Regulations (CFR) Part 63 [DIRS 156605], states that for a license to be issued for operation of a high-level radioactive waste repository, the U.S. Nuclear Regulatory Commission (NRC) must find that the facility will not constitute an unreasonable risk to the health and safety of the public (Section 63.41[c] [DIRS 156605]). Section 63.21(c)(5) [DIRS 156605] requires that a preclosure safety analysis (PCSA) be performed to ensure that the preclosure performance objectives (Section 63.111 [DIRS 156605]) have been met. The PCSA is a systematic examination of the site, the design, and the potential hazards (Section 63.102[f] [DIRS 156605]), including a comprehensive identification of potential event sequences. Potential naturallyoccurring hazards include those event sequences that are initiated by earthquake ground motions or fault displacements due to earthquakes.

According to Section 63.2 [DIRS 156605], design bases for the repository should include consideration of severe natural events, such as earthquakes. The preclosure performance objectives for the geologic repository operations area are given in Section 63.111 [DIRS 156605] and it is required that the license application (LA) show the relation between design criteria and meeting the preclosure performance objectives (Section 63.21[c][3][ii] [DIRS 156605]). The measure of acceptable risk is expressed in terms of allowable consequences versus probability of occurrence of event sequences. Allowable consequences are given as performance objectives (i.e., dose limits) in Section 63.111 [DIRS 156605] versus the probability of occurrence, expressed as Category 1 or Category 2 event sequences as defined in Section 63.2 [DIRS 156605].

The PCSA must also include a discussion of the design and how design criteria are related to design bases such that compliance with the preclosure performance objectives is assured (Section 63.112 [f] [DIRS 156605]). This topical report responds to these requirements of Part 63 with respect to preclosure seismic design, and it describes the seismic design methodology and acceptance criteria that the DOE intends to use to provide reasonable assurance of achieving the preclosure performance objectives contained in Section 63.111 [DIRS 156605].

This revision to the topical report supercedes Revision 2 issued in 1997 (YMP 1997 [DIRS 100521]) and has been updated to include appropriate reference to 10 CFR Part 63 [DIRS 156605], rather than 10 CFR Part 60 [DIRS 103540], as well as the recently finalized Yucca Mountain Review Plan (NRC 2003 [DIRS 163274]). In addition, this revision reflects consideration of recent seismic design experience and regulatory decision-making that has occurred during the past several years. These activities provide a context and precedence for the seismic design methodologies put forward in this document.

10 CFR Part 63 [DIRS 156605] does not provide guidance regarding the appropriate preclosure seismic design methodology that should be implemented or the technical criteria that should be satisfied to meet the regulatory requirements. Therefore, the DOE is submitting this topical 
report for NRC staff review and acceptance as an acceptable technical approach to the preclosure design of the geologic repository operations area for vibratory ground motion and fault displacement.

This document provides the methodology for preclosure seismic design, which includes establishment of the seismic design basis ground motion and fault displacement hazard levels for structures, systems, and components (SSCs) that are important to safety (ITS) and credited with preventing the initiation of, or mitigating the consequences of a seismically initiated event sequence. The identification of SSCs ITS occurs as part of the PCSA. After SSCs ITS have been evaluated for their risk significance, in terms of potential consequences, in seismically initiated event sequences, the appropriate seismic design basis ground motion is assigned to each SSC to ensure that the probability of occurrence of each seismically initiated event sequence meets the risk-informed performance criteria of 10 CFR 63.111 [DIRS 156605]. This topical report describes a two-pronged approach to demonstrating the adequacy of design basis ground motions assigned to particular SSCs ITS. The first is a "beyond design basis ground motions" analysis in which the seismic capacity of SSCs ITS is compared to the seismic demand associated with ground motions that are larger than the design basis ground motions. The second is an analysis of the seismic margin of SSCs ITS, which is the ability of SSC to maintain safety function at ground motions larger than the design basis ground motions. The objective of the seismic margin analysis is to demonstrate that there is "high confidence of a low probability of failure" (HCLPF), where failure is defined as unacceptable performance that can lead to not meeting the performance objectives of 10 CFR 63.111 [DIRS 156605]. The ground motion levels defined by the HCLPF capacities are demonstrated to equal or exceed the seismic demands associated with the beyond design basis ground motions.

\subsection{BACKGROUND}

This report is the third revision of the second of two topical reports on seismic hazards and preclosure seismic design of the planned geologic repository at Yucca Mountain, Nevada. The first seismic topical report (STR\#1), Methodology to Assess Fault Displacement and Vibratory Ground Motion Hazards at Yucca Mountain (YMP 1997 [DIRS 100522]), described the methodology to be used to evaluate the vibratory ground motion and fault displacement seismic hazard at Yucca Mountain. The topical report was reviewed by the NRC staff and, after comment resolution, concluded that they have no further questions related to it, pending review of all three topical reports. Subsequently, the seismic hazard methodology was implemented (CRWMS M\&O 1998 [DIRS 103731]) and the results of that probabilistic seismic hazard analysis (PSHA) provide a basis for subsequent seismic design inputs, for use in both preclosure design and postclosure performance assessments.

The initial issue and first revision of the second seismic topical report, Preclosure Seismic Design Methodology for a Geologic Repository at Yucca Mountain (STR\#2) (YMP 1997 [DIRS 100521]) describes the preclosure seismic design methodology that will be used for SSCs ITS. STR\#2 describes criteria and procedures for determining design basis vibratory ground motions in terms of the mean annual exceedance probabilities for SSCs ITS. The mean annual probability of exceedance (MAPE) is termed the "hazard" level in this document and in seismic design practice. Thus a lower hazard level indicates a lower mean annual probability of exceedance, or higher amplitudes of ground motion. For example, a hazard level of $1 \times 10^{-3} / \mathrm{yr}$ 
would be associated with a lower amplitude of ground motion than a hazard level of $1 \times 10^{-4} / \mathrm{yr}$. Design procedures and acceptance criteria are also specified in the initial issue of STR\#2 to be those associated with applicable parts of NUREG-0800 (NRC 1987 [DIRS 103124]). STR\#2 also includes a strategy for the mitigation of fault displacement hazards, which includes criteria for fault avoidance and, in those cases where 'Type I' faults (defined in McConnell et al. 1992, Section 3.1.3 [DIRS 105205]) cannot be avoided, the report describes criteria and procedures for fault displacement design. The second topical report was reviewed by the NRC staff and, after comment resolution, the reviewers concluded that they have no further questions related to it, pending review of all three topical reports. STR\#2 is being updated herein to be consistent with 10 CFR Part 63 [DIRS 156605], the Yucca Mountain Review Plan, and recent regulatory actions regarding seismic design for nuclear facilities.

A third seismic topical report (STR\#3) was originally planned to describe the implementation of the methodologies described in STR\#1 and STR\#2 to develop seismic inputs for preclosure design and for postclosure performance assessment. The DOE intends to provide the information originally intended for inclusion in Seismic Topical Report \#3 in another document entitled, Technical Basis Document No. 14: Low Probability Seismic Events (in preparation), and supported by technical data in two additional reports, Development of Earthquake Ground Motion Input for Preclosure Seismic Design and Postclosure Performance Assessment of a Geologic Repository at Yucca Mountain, NV (BSC 2004 [DIRS 168780]) and Characterize Framework for Seismicity and Structural Deformation at Yucca Mountain, Nevada (BSC 2004 [DIRS 168030]). These documents will cover all the information originally intended to be included in Seismic Topical Report \#3. They describe the results of the PSHA for Yucca Mountain, the methodology to develop seismic design inputs based on the PSHA results, examples of implementing the methodology, and a brief overview of how seismic inputs will be developed and used in postclosure performance analyses. Final seismic inputs for LA design will be presented in the license application and supporting calculations.

\subsection{SCOPE}

The establishment of preclosure seismic design criteria involves both preclosure safety analysis and repository design considerations. According to 10 CFR 63.2 [DIRS 156605], preclosure safety analysis means a systematic examination of the site; the design; and the potential hazards, initiating events and event sequences and their consequences (e.g., radiological exposures to workers and the public). The analysis identifies structures, systems, and components important to safety. The consideration of earthquake-related event sequences is just one part of the PCSA.

Evaluations of preclosure safety are made with respect to a reference design for the geologic repository operations area. Therefore, the fundamental SSCs of the preclosure design are evaluated in the PCSA to identify those that are ITS, in accordance with the definition of ITS given in Section 63.2 [DIRS 156605]. The seismic design methodology in this topical report neither specifies how the PCSA will be conducted, nor does it specify the seismic design basis hazard levels for specific SSCs. Rather, it provides a risk-informed methodology for establishing design basis hazard levels for those SSCs that have been determined to be ITS. The risk information that is used to assign the hazard level determining design basis ground motions comes from the PCSA. The seismic design methodology described in this document is iterative. The PCSA first identifies those SSCs ITS involved in seismically-initiated event sequences, 
design basis ground motion hazard levels are then assigned to those SSCs. If the PCSA shows for a given seismic design basis hazard level, that seismically-initiated event sequences lead to non-compliance with Section 63.111 [DIRS 156605], SSCs ITS will be redesigned to more severe seismic design bases (i.e., a lower hazard level and higher ground motions) to ensure compliance, or prevention or mitigation features will be added to ensure compliance. The relation between the scope of this topical report and the PCSA and design activities is given below in Sections 1.2.1 and 1.2.2. The design procedures, codes, and acceptance criteria for SSCs ITS are given in this document in Section 3.2.

\subsubsection{Relation to Preclosure Safety Analysis}

The PCSA identifies event sequences, evaluates the potential for exceeding the preclosure performance objectives in Section 63.111 [DIRS 156605], and identifies SSCs ITS. Those SSC ITS involved in seismically initiated event sequences are subject to seismic design bases and criteria given in this document. Preliminary safety classification of SSCs, as well as consideration of seismically-initiated event sequences, are performed to support the submittal of the LA. In addition to identifying SSCs ITS, the PCSA provides the event sequence and consequence information needed to establish seismic design basis hazard levels that are riskinformed. The seismic design basis ground motions hazard levels are risk-informed, such that the hazard level decreases (i.e., the severity of the design motions increases) with increasing safety importance of the SSCs. As will be discussed later in this document (Section 3.1) the PCSA will identify those SSCs ITS, and associated event sequences, that lead to progressively higher relative levels of risk significance. The assignment of design basis ground motions hazard levels can then occur in light of the risk significance. The PCSA will then incorporate those design basis ground motions hazard levels in the evaluation of the PCSA in accordance with the preclosure performance objectives in 10 CFR 63.111 [DIRS 156605]. The evaluation of seismically initiated event sequences in the PCSA will be documented in the LA.

\subsubsection{Relation To Preclosure Repository Design And Postclosure Performance Assessment}

The result of exercising the seismic design methodology in this topical report will be design basis ground motions (DBGM) at appropriate hazard levels for preclosure seismic design of SSCs ITS. The DBGMs are expressed as ground motion response spectra for appropriate mean annual probabilities of exceedance. The actual response spectrum for ground motions associated with a particular DBGM level depends on the specific location where it is applied and is developed as part of the ground motion inputs (BSC 2004 [DIRS 168780]). For example, for the same annual probability of exceedance, the ground motions at the Dry Transfer Facility 1 (at the surface) will differ from those in the emplacement drifts. Depending on the location and configuration of a particular SSC, additional location specific evaluations may be required (e.g., in-structure floor response spectra may be needed for design of an SSC within a building). After assignment to a particular DBGM hazard level and appropriate modification of the motions to make them location-specific, the ground motions will be incorporated into the project design guides and other engineering documents. Likewise, applicable elements of the Standard Review Plan (NRC 1987 [DIRS 103124]) will become part of design requirements. As discussed in Section 4, the fundamental approach to mitigating the effects of fault displacement will be fault 
avoidance. If fault avoidance is not possible, design basis fault displacements will be incorporated into the design.

The methods described for seismic design in this topical report are specifically applicable to preclosure seismic design and to demonstrating compliance with preclosure performance objectives of 10 CFR Part 63.111 [DIRS 156605]. There are no explicit seismic design requirements for postclosure, but the effects of seismic hazards (vibratory ground motion and fault displacement) on postclosure performance assessment are being evaluated in the total system performance assessment for LA (TSPA-LA). Postclosure seismic effects include vibratory ground motion induced rockfall in the emplacement drifts, damage to the drip shields due to rockfall, potential direct damage to waste packages from vibratory ground motion, and potential damage to drip shields and waste packages due to fault displacement. All of these effects are described in the Seismic Consequences Abstraction (BSC 2004 [DIRS 167780]) and their effect on postclosure performance will be calculated as part of the TSPA-LA.

\subsubsection{Assumptions and Limitations}

There are no assumptions or limitations to the methodology given in this document.

\subsubsection{Quality Assurance}

The applicability of the Quality Assurance (QA) program is limited to LP-3.11Q Technical Reports.

\subsection{ORGANIZATION OF THIS REPORT}

Following the introduction in Section 1, Section 2 of this report provides a summary of the regulatory framework for the seismic design methodology outlined in this document. The framework includes the applicable regulations specific to Yucca Mountain, NRC regulatory precedents for other nuclear facilities, and seismic design practice for non-NRC regulated nuclear facilities. Section 3 provides the seismic design basis ground motions to be invoked for SSCs ITS, summarizes the analyses that will be conducted to assure the seismic design will lead to adequate seismic margins to meet preclosure performance objectives, and outlines the design procedures and acceptance criteria that will be followed. Approaches to mitigate fault displacement hazards are given in Section 4. Section 5 summarizes the conclusions of this report and the references are given in Section 6. Appendix A describes the beyond-design basis analyses that will be conducted to demonstrate that SSCs ITS will maintain their intended safety functions when submitted to ground motions that exceed their design basis ground motions. Appendix B describes the methodology for developing high confidence of low probability of failure (HCLPF) estimates of seismic margin for SSCs ITS.

\section{REGULATORY FRAMEWORK}

This section describes NRC regulations and regulatory actions regarding seismic design levels at NRC-regulated nuclear facilities. DOE criteria and approaches to establishing seismic design levels are also described. 


\subsection{CFR PART 63 "DISPOSAL OF HIGH-LEVEL RADIOACTIVE WASTES IN A PROPOSED GEOLOGIC REPOSITORY AT YUCCA MOUNTAIN, NEVADA”}

Section 63.41(c) [DIRS 156605] specifies that the issuance of a license to receive and possess high-level radioactive waste requires a demonstration that the geologic repository operations area will not constitute an unreasonable risk to the health and safety of the public. The measure of acceptable risk is expressed in terms of allowable consequences versus probability of occurrence of event sequences. Allowable consequences are given as performance objectives (i.e., dose limits) in Section 63.111 [DIRS 156605] versus the probability of occurrence, expressed as Category 1 or Category 2 event sequences as defined in Section 63.2 [DIRS 156605]. The PCSA will identify event sequences and their mean frequency of occurrence. Section 63.2 [DIRS 156605] defines event sequences as:

"Event sequence means a series of actions and/or occurrences within the natural and engineered components of a geologic repository operations area that could potentially lead to exposure of individuals to radiation. An event sequence includes one or more initiating events and associated combinations of repository system component failures, including those produced by the action or inaction of operating personnel.”

Thus, in the PCSA, an event sequence is identified as beginning with an initiating event (from an identified hazard) that is followed by one or more events that must occur to result in a release of radioactivity, criticality, or an abnormal exposure of a worker. Event sequence categorization is based on the mean frequency of the entire sequence of events and not just the frequency of the initiating event. Using the definitions from 10 CFR Part 63.2 [DIRS 156605], the event sequence categories are quantified as:

- Category 1-Event sequences expected to occur one or more times before permanent closure (assuming a nominal preclosure period of 100 years, such sequences would have an annual probability or frequency greater than or equal to $1 \times 10^{-2} / \mathrm{yr}$ ).

- Category 2-Event sequences that have at least one chance in 10,000 of occurring before permanent closure (assuming a nominal preclosure period of 100 years, such sequences would have an annual probability or frequency of at least $1 \times 10^{-6} / \mathrm{yr}$ and less than $\left.1 \times 10^{-2} / \mathrm{yr}\right)$.

These definitions are presented for background. Categorizing event sequences is important because it establishes the portion of the preclosure performance objectives (10 CFR 63.111 [DIRS 156605]) that must be met for an event sequence. For seismically initiated event sequences, however, it is the corresponding performance objectives that are applied to establish two-tiered, risk-informed seismic design bases. As will be discussed in Section 3.1, the application of the seismic design bases will preclude the occurrence of any seismically initiated event sequence having a mean annual probability of $1 \times 10^{-3}$ or greater and, therefore, precludes the occurrence of a Category 1 seismically initiated event sequence. 


\subsubsection{Preclosure Performance Objectives}

\section{Category 1 Event Sequences}

A limit of $0.15 \mathrm{mSv} / \mathrm{year}$ is defined for Category 1 events, from 10 CFR 63.111(b)(1) [DIRS 156605]:

“(1) The geologic repository operations area must be designed so that, taking into consideration Category 1 event sequences and until permanent closure has been completed, the aggregate radiation exposures and the aggregate radiation levels in both restricted and unrestricted areas, and the aggregate releases of radioactive materials to unrestricted areas, will be maintained within the limits specified in paragraph (a) of this section.”

And referencing 10 CFR 63.111(a) [DIRS 156605]:

“(a) Protection against radiation exposures and releases of radioactive material.

(1) The geologic repository operations area must meet the requirements of part 20 of this chapter.

2) During normal operations, and for Category 1 event sequences, the annual TEDE (hereafter referred to as "dose”) to any real member of the public located beyond the boundary of the site may not exceed the preclosure standard specified at §63.204.”

And referencing 10 CFR 63. 204 [DIRS 156605]:

“§63.204 Preclosure standard.

DOE must ensure that no member of the public in the general environment receives more than an annual dose of $0.15 \mathrm{mSv}$ (15 mrem) from the combination of:

(a) Management and storage (as defined in 40 CFR 191.2) of radioactive material that: ...

(b) Storage (as defined in §63.202) of radioactive material inside the Yucca Mountain repository."

The dose limits given in 10 CFR 20.1202 to 1208 and 10 CFR 20.1301 to 1302 [DIRS 104787] must also be maintained for Category 1 event sequences.

\section{Category 2 Event Sequences}

The limits for Category 2 events are defined in 10 CFR 63.111(b)(2) [DIRS 156605]:

“(2) The geologic repository operations area must be designed so that, taking into consideration any single Category event sequence and until permanent closure has 
been completed, no individual located on, or beyond, any point on the boundary of the site will receive, as a result of the single Category 2 event sequence, the more limiting of a TEDE of $0.05 \mathrm{~Sv}$ ( $5 \mathrm{rem}$ ), or the sum of the deep dose equivalent and the committed dose equivalent to any individual organ or tissue (other than the lens of the eye) of $0.5 \mathrm{~Sv}$ (50 rem). The lens dose equivalent may not exceed $0.15 \mathrm{~Sv}$ (15 rem), and the shallow dose equivalent to skin may not exceed $0.5 \mathrm{~Sv}$ (50 rem).”

\subsubsection{Preclosure Safety Analysis}

According to Section 63.21(c)(5) [DIRS 156605], the Safety Analysis Report of the License Application must include: "A preclosure safety analysis of the geologic repository operations area, for the period before permanent closure, to ensure compliance with §63.111(a) [DIRS 156605], as required by §63.111(c) [DIRS 156605].” As defined in Section 63.2 [DIRS 156605]:

"Preclosure safety analysis means a systematic examination of the site; the design; and the potential hazards, initiating events and event sequences and their consequences (e.g., radiological exposures to workers and the public). The analysis identifies structures, systems, and components important to safety."

Section 63.102(f) [DIRS 156605] further describes the preclosure safety analysis, including consideration of initiating events for event sequences:

“(f) Preclosure safety analysis. Section 63.111 includes performance objectives for the geologic repository operations area for the period before permanent closure and decontamination or permanent closure, decontamination, and dismantlement of surface facilities. The preclosure safety analysis is a systematic examination of the site; the design; and the potential hazards, initiating events and their resulting event sequences and potential radiological exposures to workers and the public. Initiating events are to be considered for inclusion in the preclosure safety analysis for determining event sequences only if they are reasonable (i.e., based on the characteristics of the geologic setting and the human environment, and consistent with precedents adopted for nuclear facilities with comparable or higher risks to workers and the public). The analysis identifies structures, systems, and components important to safety."

The language of 10 CFR 63.102 [DIRS 156605] provides for the inclusion of initiating events in preclosure safety analyses only if they are reasonable, as defined above. The Federal Register notice for the issuance of the final rule of 10 CFR Part 63 [DIRS 156605] provided discussions of public comments and NRC responses on the draft rule. With regard to initiating events, the following text states that the initiating event must be reasonable (66 FR 55732; p. 55741 [DIRS 156671]): 
"The two critical aspects of the PSA ${ }^{1}$ in the context of this issue are (1) the identification of the event sequences that have probabilities greater than or equal to one chance in 10,000 of occurring before permanent closure and (2) the associated dose consequences. Following the intent of risk-informed performance-based regulation, designation of specific design basis criteria in the regulation is not appropriate. The goal of the DOE design activity should be to demonstrate that the dose limits expressed in $\S 63.111$ will be met, taking into consideration site-specific information regarding the geologic setting and human activities in the surrounding environs. For example, if a hazard (or the low probability events of the hazard spectrum) is deemed unreasonable for the Yucca Mountain site, DOE can exclude it from consideration in the PSA provided proper technical justification is presented in accordance with §63.112(d). Thus, while the regulation specifies a lower limit on the probability of event sequences, the risk-informed NRC regulation anticipates that DOE will develop a clear technical basis for the event sequences included/excluded from the PSA.”

Importantly, the intent of the regulation is not to specify the lower "cut-off" or reference limit probability for an initiating event, but allows for restricting the initiating event based on precedent or other arguments (66 FR 55732; pp. 55741 [DIRS 156671]):

"The Commission did not intend to specify cut-off probabilities for initiating events but recognizes that certain initiating events may not be appropriate for inclusion in the PSA. Therefore, the rule, at §63.102(f), has been revised to include the following description of considerations that can be used by the DOE to limit the inclusion of initiating events in the PSA:

Initiating events are to be considered for inclusion in the preclosure safety analysis for determining event sequences only if they are reasonable (i.e., based on the characteristics of the geologic setting and the human environment, and are consistent with precedents adopted for nuclear facilities with comparable or higher risks to workers and the public)."

In addition, the intent of the regulation is specifically to allow DOE to select the initiating events. However, this will require that DOE defend the selection of initiating events (66 FR 55732; p. 55742 [DIRS 156671]):

"Within the context of the ISA (PSA), DOE is expected to identify the relevant initiating events and event sequences and estimate potential radiologic exposures. Part 63 provides flexibility to DOE in selecting an appropriate approach for estimating doses, including selection of pertinent exposure pathways and the degree of conservatism or realism to include in the analysis. DOE will need to defend and support whatever approach it selects for identifying initiating events and analyzing event sequences. In the selection of a particular approach, DOE

\footnotetext{
${ }^{1}$ Acronym for preclosure safety analysis used in this report is PCSA. 66 FR 55732 and 55741 uses the acronym
} PSA 
will need to consider the uncertainties and limitations associated with a particular method of analysis and data."

In specifying the requirements for the PCSA, Section 63.112(b) [DIRS 156605] makes it clear that the potential initiating events for consideration in the event sequences are naturally occurring events such as earthquake-related effects:

“(b) An identification and systematic analysis of naturally occurring and human-induced hazards at the geologic repository operations area, including a comprehensive identification of potential event sequences;”

Finally, a key function of the PCSA is to identify those SSCs that are ITS. Per Section 63.112(e) [DIRS 156605]:

“(e) An analysis of the performance of the structures, systems, and components to identify those that are important to safety. This analysis identifies and describes the controls that are relied on to limit or prevent potential event sequences or mitigate their consequences. This analysis also identifies measures taken to ensure the availability of safety systems...”

Those SSCs ITS that have been identified in event sequences having an earthquake-related initiating event will be those subject to the seismic design methodology described in this report.

\subsubsection{Design Bases and Design Criteria}

Per Section 63.21(c)(3) [DIRS 156605], the Safety Analysis Report in the License Application must include:

"(3) A description and discussion of the design of the various components of the geologic repository operations area and the engineered barrier system including:

(i) Dimensions, material properties, specifications, analytical and design methods used along with any applicable codes and standards;

(ii) The design criteria used and their relationships to the preclosure and postclosure performance objectives specified at §63.111(b), §63.113(b), and $\S 63.113(\mathrm{c})$; and

(iii) The design bases and their relation to the design criteria.”

For clarification, design bases are defined in Section 63.2 [DIRS 156605]:

"Design bases means that information that identifies the specific functions to be performed by a structure, system, or component of a facility and the specific values or ranges of values chosen for controlling parameters as reference bounds for design. These values may be constraints derived from generally accepted "state-of-the-art" practices for achieving functional goals or requirements derived from analysis (based on calculation or experiments) of the effects of a postulated 
event under which a structure, system, or component must meet its functional goals. The values for controlling parameters for external events include:

(1) Estimates of severe natural events to be used for deriving design bases that will be based on consideration of historical data on the associated parameters, physical data, or analysis of upper limits of the physical processes involved.”

Therefore, the PCSA identifies the SSCs ITS by a systematic evaluation of event sequences, including those with seismic initiating events, and identifies the design bases that are needed to assure compliance with the preclosure performance objectives. The regulation does not specify design bases, but leaves that to the DOE. According to requirements for the PCSA, Section 63.112(f) [DIRS 156605] specifies that it include:

“f) A description and discussion of the design, both surface and subsurface, of the geologic repository operations area, including--

(1) The relationship between design criteria and the requirements specified at §63.111(a) and (b); and

(2) The design bases and their relation to the design criteria.”

This topical report directly responds to the requirement to provide seismic design bases and design criteria for those SSCs determined to be ITS. The implementation of the seismic design methodology and criteria given in the report will be documented in the PCSA section of the LA.

\subsection{YUCCA MOUNTAIN REVIEW PLAN}

The Yucca Mountain Review Plan (NRC 2003 [DIRS 163274]) provides insight into the NRC staff's expectations and emphasis during review of the LA, and, as such, provides a context for the development of a preclosure seismic design methodology and criteria that will meet the staff's expectations.

The Yucca Mountain Review Plan states (NRC 2003, Section 2.1.1 p. 2.1-2 [DIRS 163274]) that the development of specific design criteria is left to the DOE:

"No prescriptive design criteria are imposed in the Yucca Mountain Review Plan, because 10 CFR Part 63 allows the U.S. Department of Energy to develop the design criteria and demonstrate their appropriateness. Thus, the U.S. Department of Energy has flexibility to use any codes, standards, and methodologies it demonstrates to be applicable and appropriate. This flexibility is necessary when implementing a risk-informed, performance-based regulation. The risk-informed, performance-based review process in the Yucca Mountain Review Plan focuses on determining compliance with performance objectives as demonstrated by the U.S. Department of Energy preclosure safety analysis.”

It is in this context that the seismic design criteria and methodology described in this document will be presented for review and acceptance by the NRC. 
In the process of identifying hazards and initiating events for the PCSA, the Yucca Mountain Review Plan (NRC 2003, Section 2.1.1.3, Review Method 1, p. 2.1-20 [DIRS 163274]) requests that the staff "confirm that methods used to identify hazards and initiating events are consistent with Agency guidance or standard industry practices...If Agency guidance or standard industry practices are not used by the U.S. Department of Energy, evaluate whether the U.S. Department of Energy basis and justification for choosing a particular hazard and initiating event identification method are defensible." Further, the staff is directed to verify that appropriate site-specific data have been used to identify naturally-occurring hazards and initiating events, including seismicity and faulting (NRC 2003, Section 2.1.1.3, Review Method 2, p. 2.1-20 [DIRS 163274]).

Relevant to design criteria and design bases, the Yucca Mountain Review Plan directs the staff to "verify that design criteria and bases have been identified for structures, systems, and components ITS” (NRC 2003, Section 2.1.1.7.2.1, Review Method 1, p. 2.1-52 [DIRS 163274]). The adequacy of design bases and design criteria is to be judged based on the PCSA and, in particular for seismic design, consistency with NRC guidance is called for (Section 2.1.1.7.2.1, Review Method 1, p. 2.1-52 to 2.1-53):

"Verify that design criteria adequately consider preclosure safety analysis results. Verify that structures, systems, and components important to safety will continue to prevent consequences, such as unacceptable releases of radioactive material, unacceptable radiation doses for workers or the public, and loss of removal capability.

Confirm that structural design criteria and bases for structures, systems, and components ITS are consistent with relevant U.S. Nuclear Regulatory guidance for tornado protection, seismic design, explosion protection, and flood protection.”

Regarding fault displacement hazard, the design of subsurface operating systems can only be found adequate if "emplacement drifts are located away from major faults, consistent with the seismic design” (NRC 2003, Section 2.1.1.7.3.3[ii], Acceptance Criterion 2, p. 2.1-70 [DIRS 163274]). In addition, the Yucca Mountain Review Plan indicates that it should be shown that "the dynamic loads used in design analyses are consistent with seismic-design ground-motion parameters, consider faulting effects, and are consistent with accepted methodologies for assessing faulting hazards” (NRC 2003, Section 2.1.1.7.3.3[ii], Acceptance Criterion 4, p. 2.1-71 [DIRS 163274]).

Consistent with the NRC's risk-informed regulatory policy, the Yucca Mountain Review Plan indicates that the staff's review of the preclosure safety analysis will be risk-informed. Likewise, it is expected that DOE's preclosure safety analysis will focus on SSCs that are ITS. Further, it is expected that SSCs ITS may be further distinguished by their relative risk significance (NRC 2003, Section 2.1.1, p. 2.1-1 [DIRS 163274]):

“The structures, systems, and components important to safety may also be further categorized, based on relative safety significance, using risk information from the preclosure safety analysis. This distinction may be used to focus on the level of 
design details to be provided in the license application and the application of quality assurance controls... The staff review is focused on items that the preclosure safety analysis has determined to be important to safety. The rigor of review for the design items on the Q-List, and the level of attention to detail, depend on relative safety significance.”

As anticipated in the Yucca Mountain Review Plan, the seismic design methodology described in this report will utilize the risk information developed in the PCSA to, first, identify the SSCs that are ITS and, second, to further define their risk significance such that the level of seismic design basis ground motions and the level of fault displacement hazard is appropriate for the relative risk significance of SSC ITS.

\subsection{SEISMIC DESIGN OF NUCLEAR POWER PLANTS AND OTHER NUCLEAR FACILITIES}

An important regulatory context for the preclosure seismic design methodology for Yucca Mountain are regulations and regulatory guidance that are relied upon by the NRC and other agencies for determining the seismic safety at other nuclear facilities. Current regulations require, and regulatory guidance provides for, PSHA as the fundamental means of characterizing the seismic environment at a site, and for the determination of appropriate seismic design basis ground motion hazard levels based on a consideration of the risk significance of SSCs ITS. Deterministic approaches to defining seismic design levels for nuclear power plants (10 CFR Part 100, Appendix A [DIRS 130595]) have been replaced by approaches based on PSHA (10 CFR 100.23). To implement PSHA requirements, an annual probability of exceedance (synonymously referred to as a reference probability, design hazard level, or design earthquake) must be established for SSC ITS. The establishment of these design basis hazard levels in NRC regulations is now risk-informed in that the design basis ground motions are higher (i.e., the annual probability hazard level is lower) for nuclear power plants than for other nuclear facilities such as independent spent fuel storage installations. These differences in the design basis ground motion hazard levels are justified by the differences in the potential consequences or risk associated with seismically-induced failure of the facilities.

Regulatory Guide 1.165 (1997, Appendix B [DIRS 119139]) for new nuclear power plants states that the design basis ground motion should be associated with a median probability $1 \times 10^{-5}$ per year. Taking into consideration the probability distribution of seismic hazard curves at typical locations, a median annual probability of $1 \times 10^{-5}$ is approximately equivalent to a mean annual probability of $1 \times 10^{-4}$. This observation has been cited in recent findings of the partial initial decision regarding Private Fuel Storage's independent spent fuel storage installation.

Specifically, it was stated in Finding F.103 (United States of America Nuclear Regulatory Commission, Atomic Safety and Licensing Board before Administrative Judges: Michael C. Farrar, Chairman, Dr. Jerry R. Kline and Dr. Peter S. Lam, in the Matter of Private Fuel Storage (Independent Spent Fuel Storage) 2003, p. 333 [DIRS 165665]):

“... In Regulatory Guide 1.165, based on an analysis of the SSEs for existing NPPs [nuclear power plants], the Staff established the appropriate Reference Probability to determine the SSE at future NPP sites in connection with the use of 
a PSHA approach under $10 \mathrm{CFR}$. \$100.23; the Reference Probability was determined to be a $1 \times 10^{-5}$ MAPE (approximately equivalent to a 100,000 - year return period). As the Staff explained, this Reference Probability, which is defined in terms of the median probability of exceedance, corresponds to a MAPE [mean annual probability of exceedance] of $1 \times 10^{-4}$. That is, the same design ground motion that has a median reference probability of $1 \times 10^{-5}$, has a MAPE of $1 \times 10^{-4}$ _(Stamatakos/Chen/McCann Post 8050, at 19)." (underline added for emphasis and brackets added for clarification)

For nuclear-related facilities other than nuclear power plants, the NRC and NRC staff have approved seismic design basis ground motions that are probabilistically based and that have mean annual probabilities of exceedance in the range of $4 \times 10^{-4} /$ year to $5 \times 10^{-4} /$ year:

NRC approved Private Fuel Storage's independent spent fuel storage installation seismic design on 22 May 2003 (United States of America Nuclear Regulatory Commission, Atomic Safety and Licensing Board before Administrative Judges: Michael C. Farrar, Chairman, Dr. Jerry R. Kline and Dr. Peter S. Lam, in the Matter of Private Fuel Storage [Independent Spent Fuel Storage] p 326 2003) [DIRS 165665]). The design was based on a PSHA with a MAPE of $5 \times 10^{-4} /$ year seismic design basis event, based on an approved exemption to 10 CFR 72.102(f)(1) (Parkyn 1999 [DIRS 165667]).

The Mixed Oxide Fuel Fabrication Facility utilized a PSHA and a seismic hazard exceedance mean probability criterion which envelops the $5 \times 10^{-4}$ /year event (Ihde 2001, pp. 1.3.6-23 [DIRS 165661]) with reference to DOE Criteria for Performance Category 3 (PC-3) (DOE-STD-1020-94 [DIRS 161324]). The DOE Performance Categories are discussed below in this section.

Foster Wheeler utilized a PSHA and a MAPE of $4.0 \times 10^{-4} /$ year (a 2500-year mean return period) for the design of the Idaho Spent Fuel Facility based on DOE Criteria for Performance Category 3 (PC-3) (Idaho Spent Fuel Facility 2001, pp. 2.6-34 to 35 and 2.7-1 [DIRS 165662]). The license also included a request for exemption to 10 CFR 72.102(f)(1) (Rogers 2001, Appendix A [DIRS 165663]).

The NRC has recently adopted a final rule that makes significant revisions to 10 CFR Part 72 [DIRS 103541] (Travers 2003 [DIRS 165666]). The revised regulation requires a PSHA for determining the seismic DBGMs for a site (Travers 2003 [DIRS 165666]):

"The final rule will make the 10 CFR Part 72 regulations compatible with the 1996 revision to Part 100 that addressed uncertainties in seismic hazard analysis. Specifically, the final rule changes will require a new specific-license applicant for a dry cask storage facility located in either the western U.S. or in areas of known seismic activity in the eastern U.S., and not co-located with an NPP, to address uncertainties in seismic hazard analysis by using appropriate analyses, such as a PSHA or other suitable sensitivity analyses, for determining the design earthquake ground motion (DE)." 
The NRC also adopted a risk-informed approach to identifying the design basis ground motion level, taking into consideration the differences in risk between a nuclear power plant and an independent spent fuel storage installation (ISFSI) or monitored retrievable storage (MRS) facility (Travers 2003 [DIRS 165666]):

"The staff also believes that the potential radiological consequences of a seismic event at an ISFSI or MRS storing spent fuel in dry casks or canisters are substantially less than the potential consequences of a similar event at an NPP. Therefore, the final rule will allow an ISFSI or MRS applicant to use a design earthquake level commensurate with the risk associated with an ISFSI or MRS, and thus the rule will be risk-informed and complies with the Commission's policies on probabilistic risk assessment and performance goals. The accompanying Regulatory Guide 3.73 (Attachment 3) recommends an acceptable design earthquake level. The staff's analysis and the basis for the recommendation is provided in the White Paper entitled, "Selection of the Design Earthquake Ground Motion Reference Probability.”

The White Paper (Attachment 4 to Travers 2003 [DIRS 165666]) referred to in the rulemaking provides an evaluation of the risk posed by an ISFSI or MRS facility and compares the potential earthquake-induced consequences with those that could occur at a nuclear power plant. It is concluded that because the risks associated with an ISFSI or MRS are significantly less than those posed by a nuclear power plant, the design basis ground motions (termed the "design earthquake" or DE) should, following a risk-informed regulatory policy, likewise be lower or less severe (Travers 2003, Attachment 4, p. 6 [DIRS 165666]):

"In a risk-informed, performance-based approach, the earthquake design level of the facility is selected based on the degree of risk associated with the facility."

The mean annual probability associated with the design basis ground motions is identified as $5 \times 10^{-4}$ (2,000 yr return period) for an ISFSI or MRS, and this design level is compared with design levels for other facilities (Travers 2003, Attachment 4, Section 3.4, p. 12 [DIRS 165666]):

"1. Based on the fact that the risk from an earthquake at a dry cask ISFSI or MRS facility is lower than at an NPP, the reference probability for such a facility should be higher than the reference probability of $1 \mathrm{E}-4$ for an NPP. In other words, the design-mean earthquake return period for such a facility should be less than 10000 years.

2. The reference probability of 5E-4 (2000-year return period), for an ISFSI or MRS facility DE, is consistent with that used in DOE-STD-1020, for similar-type facilities.

3. The IBC-2000 requires the buildings, similar to a dry cask ISFSI or MRS facility, to be designed for earthquakes for a return period varying from 500 to 1300 years. Therefore, the recommended reference probability of 5E-4 
(2000-year return period) provides more stringent seismic design criteria than the IBC-2000 seismic design requirements.”

For many years, the DOE has implemented a risk-informed graded approach to seismic design in their Natural Phenomena Hazards Design and Evaluation Criteria for Department of Energy Facilities (DOE-STD-1020-2002 [DIRS 159258]). SSCs ranging from nuclear reactors, non-reactor nuclear facilities, essential buildings, and conventional buildings are categorized into four performance categories according to their risk significance. The design basis ground motion probability levels for seismic design, as well as the performance goals, are tied to the performance categories. Performance Category 3 (PC-3) (DOE-STD-1020-2002, p. 25 [DIRS 159258]) indicates a design basis mean annual exceedance probability of $4 \times 10^{-4}$ (2500 yr return period) for sites away from active tectonic plate boundaries (where the slopes of hazard curves may be different). Design forces are multiplied by a Scale Factor of 0.9 to bring the design basis ground motion hazard levels to approximately $5 \times 10^{-4}$ (2000-year return period).

\subsection{NUREG-0800, STANDARD REVIEW PLAN}

NUREG-0800 (NRC 1987 [DIRS 103124]) provides guidance to the Office of Nuclear Reactor Regulation staff who are responsible for the review of applications to construct and operate nuclear power plants. NUREG-0800 applies only to nuclear power reactors and is not applicable to mined geologic repository systems. However, as discussed in Section 2.1.4, the Yucca Mountain Review Plan (NRC 2003 [DIRS 163274]) does not provide specific seismic design acceptance criteria, as does NUREG-0800. For this reason, the DOE has evaluated the sections of NUREG-0800 that directly relate to seismic design methodology for potential applicability to mined geologic repository systems. Specific Standard Review Plan sections and their applicability are given in Section 3.2 of this report.

\section{DESIGN BASIS GROUND MOTIONS AND DESIGN PROCEDURES}

This section describes the design basis ground motion levels that will be assigned for SSCs determined by the PCSA to be ITS and credited with preventing the initiation of, or mitigating the consequences of a seismically initiated event sequence. The assignment of DBGM levels is risk-informed such that SSCs determined in the PCSA to be more risk-significant will be subjected to more severe seismic design bases. Further, the seismic event sequence analysis, the levels of DBGM, and the design procedures have all been informed by precedents in the seismic design of other nuclear facilities. For example, the identification of seismically-initiated event sequences and evaluation of the consequences of seismic shaking of many SSCs such as the buildings are assisted by similar analyses that have been conducted for comparable facilities. Likewise, the annual probabilities of exceedance used for the DBGM levels are comparable to those employed for other facilities having similar risk significance (see Section 3.4).

Acceptable seismic safety is achieved through a combination of two important design aspects: (1) the DBGM level, and (2) the conservatism in the design procedures, acceptance criteria, codes, and standards. DOE is free to choose whatever seismic design bases and design procedures it determines will provide reasonable assurance that the preclosure performance 
objectives of 10 CFR Part 63 [DIRS 156605] have been met. The use of appropriate levels of DBGMs, adoption of nuclear-power plant design procedures, and demonstration of adequate seismic margins beyond the design basis ground motions are all part of the design methodology described below. Ultimately, evaluations as part of the PCSA will demonstrate compliance to the dose standards in 10 CFR 63.111 [DIRS 156605].

\subsection{DESIGN BASIS GROUND MOTIONS FOR SSCS IMPORTANT TO SAFETY}

The seismic design basis ground motion levels are derived based on mean annual probabilities of exceedance (MAPE) and implement NRC's risk-informed regulatory policy. The amplitudes of ground motion representing appropriate risk-informed annual probabilities of exceedance are site-specific for the locations of repository components (i.e., surface and subsurface facilities) and are given in Development Of Earthquake Ground Motion Input for Preclosure Seismic Design and Postclosure Performance Assessment of a Geologic Repository at Yucca Mountain, Nevada (BSC 2004, Sections 6.3.1.2 and 6.3.1.3 [DIRS 168780])). The characterization of sitespecific ground motions by a specific measure (e.g., accelerations, velocities, response spectra, time histories) is a function of the requirements for design implementation.

\subsubsection{Design Basis Ground Motion Levels}

Two design basis ground motion (DBGM) levels will be used for the seismic design of structures, systems, and components ITS:

- DBGM-1 having a MAPE of $1 \times 10^{-3}$ (1,000 year return period)

- DBGM-2 having a MAPE of $5 \times 10^{-4}$ (2,000 year return period).

The determination of appropriate DBGM levels for specific SSCs depends on their risk significance, as evaluated in the PCSA. The methodology for assessing risk significance and assigning DBGM levels is applied in analyses that support the submittal of the LA. Either DBGM-1 or DBGM-2 is assigned to a given structure, system, or component to ensure compliance with 10 CFR 63.111(b)(1) and (2) [DIRS 156605], respectively, for seismically initiated event sequences. In addition, DBGM-2 is assigned to a SSC that is necessary to prevent a seismically initiated event sequence that could lead to a criticality. The assignment is tied to the dose limits established in the performance requirements of 10 CFR 63.111 [DIRS 156605] (with reference to 10 CFR 63.204 [DIRS 156605] and 10 CFR 20.1201 [DIRS 104787]) for Category 1 and Category 2 event sequences (Table 1). As a minimum, DBGM-1 is assigned to an SSC if the seismic failure of the SSC (i.e., loss of the SSC safety function) could result in a dose equal to or greater than 5 rem TEDE to a worker or 15 mrem to the public, or if organ doses to workers or the public exceed the limits specified in 10 CFR 63.111(b)(1) [DIRS 156605]. Similarly, DBGM-2 is assigned to an SSC if the seismic failure of the SSC could result in a criticality, a dose equal to or greater than 5 rem total effective dose equivalent (TEDE) to the public, or an organ dose to the public that exceeds the limits specified in 10 CFR 63.111(b)(2) [DIRS 156605]. Should it be shown that concurrent seismic failures of multiple SSCs initially assigned to DBGM-1 could result in a public dose that exceeds the limits specified in 10 CFR 63.111(b)(2) [DIRS 156605] (e.g., 5 rem TEDE), one or more of those SSCs will have to be reassigned to the DBGM-2 category. The assignment of DBGM levels may be extended to SSCs 
that are not ITS if the seismic failure of the SSC could cause an SSC ITS to lose its safety function.

Table 1. Bases for Assigning Design Basis Ground Motion Levels to SSCs ITS

\begin{tabular}{|c|c|c|c|}
\hline $\begin{array}{c}\text { Event Sequence I } \\
\text { Category - Initiated by } \\
\text { Seismic Event }\end{array}$ & Person Type & $\begin{array}{l}\text { Consequences of Loss of } \\
\text { SSC Safety Function } \\
\text { Single Sequence Dose } \\
\text { Limit - TEDE }^{1}\end{array}$ & $\begin{array}{l}\text { DBGM Assigned to SSCs } \\
\text { ITS }\end{array}$ \\
\hline \multirow{3}{*}{$\begin{array}{l}\text { Category } 1 \text { Event } \\
\text { Sequences }\end{array}$} & $\begin{array}{c}\text { Radiation Worker within } \\
\text { Geologic Repository } \\
\text { Operations Area }\end{array}$ & > 5 rem (0.05 Sv) & DBGM-1 \\
\hline & $\begin{array}{c}\text { Controlled Area Worker } \\
\text { Beyond Geologic Repository } \\
\text { Operations Area } \\
\text { Or } \\
\text { Member of Public on the } \\
\text { Site and Beyond Geologic } \\
\text { Repository Operations Area } \\
\text { Or } \\
\text { NTS / Nellis Workers in } \\
\text { Unrestricted Area }\end{array}$ & $\begin{array}{c}>100 \text { mrem }(1.0 \mathrm{mSv}) \text { or } \\
>2 \text { mrem }(0.02 \mathrm{mSv}) \text { per } \\
\text { hour or } \\
>10{\text { mrem }\left(0.1 \mathrm{mSv}^{3}\right) \text { from }}_{\text {air emissions }^{3}}\end{array}$ & DBGM-1 \\
\hline & $\begin{array}{c}\text { Member of Public Beyond } \\
\text { Site Boundary, in General } \\
\text { Environment }\end{array}$ & >15 mrem (0.15 mSv ) & DBGM-1 \\
\hline $\begin{array}{l}\text { Category } 2 \text { Event } \\
\text { Sequences }\end{array}$ & $\begin{array}{l}\text { Individual at or Beyond the } \\
\text { Site Boundary }{ }^{2}\end{array}$ & $>5$ rem (0.05 Sv) & DBGM-2 \\
\hline Criticality Condition & N/A & N/A & DBGM-2 \\
\hline
\end{tabular}

NOTES:

1. Values are for TEDE (a measure of body dose). Higher dose equivalents for the lens of the eye, the skin, and the extremities are not included in the table, but are subject to separate limits per 10 CFR 63.111(b)(2) [DIRS 156605] , 10 CFR 20.1101, 10 CFR 20.1202 to 1208 and 10 CFR 20.1301 to 1302 [DIRS 104787] . For purposes of assigning DBGMs, Category 1 performance requirements are applied on a per sequence basis for seismic analyses whereas, for non-seismic event sequences, Category 1 performance requirements are applied on an aggregate basis.

2 At any point on the site boundary.

3. Limit doses do not include occupational dose or doses received from background radiation, from any medical administration the individual has received, from exposure to individual administered radioactive material and released under 10 CFR 35.75, or from voluntary participation in medical research programs.

4. $\mathrm{DBGM}=$ design basis ground motion; ITS = important to safety; NTS = Nevada Test Site; SSCS = structures, systems, and components; TEDE = total effective dose equivalent.

There are two bases for identifying SSCs ITS. The first basis is a determination of whether the SSC is credited with prevention or mitigation of event sequences for internal hazards. The initiating events and loss of credited safety functions are postulated to be caused by seismic 
failures, and DBGM levels are assigned in accordance with the dose or criticality that could result. Such seismic event sequences are postulated to cause initiating events that also could occur, otherwise, from random failures (i.e., independent of an earthquake) such as drop of waste forms by handling equipment, loss of offsite power, and fires. Depending on the design bases of various SSCs and the severity of the ground motion associated with a given earthquake, it is possible for many or all of the internal event sequences to be triggered concurrently. This potential is considered in assigning the DBGM levels and in the compliance demonstration. However, if a particular SSC is designated ITS to mitigate the consequences of a non-seismically initiated event sequence but does not need to be credited for prevention or mitigation of a seismically initiated event sequence, then that SSC may not require a DBGM assignment.

The second basis for assigning DBGMs is an analysis to identify seismically-initiated event sequences that were not identified in the internal event analysis. Such event sequences include seismic failures of passive SSCs such as transfer cell walls and ceiling, support structures of cranes and handling equipment, or disassembly of spent fuel assembly staging racks. The seismic failure (loss of safety function) of such SSCs is postulated and the potential doses are assessed. DBGM levels are assigned in accordance with the stated dose guidelines (Table 1). Again, depending on the design bases of various SSCs and the severity of the ground motion associated with a given earthquake, it is possible for the failure of passive components and the internal event sequences to be "triggered" concurrently. This potential is considered in assigning the DBGM levels and in the demonstration of compliance with 10 CFR 63.111 [DIRS 156605].

The PCSA analyses that are prepared and documented to support the LA include event sequence identification and categorization, lists of SSCs ITS that have been identified as being ITS from internal event or seismic event sequence analyses and nuclear safety design bases reports. As appropriate, SSCs that have been identified from the seismic safety analysis as necessary to prevent or mitigate radiological consequences that do not meet the requirements of 10 CFR 63 [DIRS 156605] are classified as SSCs ITS. All SSCs ITS that are credited with prevention or credited for mitigation of the radiological consequences must be assigned to one of the two DBGM categories as appropriate to the dose or criticality condition that could result from their seismic failure, unless a particular SSC does not need to be credited for prevention or mitigation of a seismically initiated event sequence.

The assignment of DBGM levels to SSCs ITS proceeds in stages:

1. Calculate the public and worker dose consequences associated with each individual seismic event sequence. This stage uses a deterministic analysis in that the event sequence is assumed to occur without consideration of the probability of its occurrence. Based on the doses calculated, DBGM-1 or DBGM-2 category is initially assigned to the SSCs whose individual seismic failure results in the calculated unacceptable dose.

2. Consider the effects of correlation between seismic failures in various facilities. For example, correlations between the two or more identical dry transfer facility buildings need to be considered such that correlated failures will result in the sum of the associated doses. For example, a given seismic sequence one dry transfer building might result in a public dose of 3 rem. By itself, this event sequence is compliant with 
10 CFR 63.111(b)(1) [DIRS 156605] and a DBGM-1 could be assigned to the affected SSCs. However, the correlated event sequence initiated at the same time in a second facility could result in an aggregated dose of $6 \mathrm{rem}$. The aggregated dose is noncompliant with 10 CFR 63.111(b)(2) [DIRS 156605], so a DBGM-2 would have to assigned to the affected SSCs in both facilities. Part of the second stage analysis is to ensure that the most limiting DBGM category is assigned to a given SSC that is associated with several seismic event sequences.

3. Evaluate the aggregated public dose that could occur if all SSCs assigned to DBGM-1 were to fail for ground motions more severe than DBGM-1. If the aggregated dose does not comply with 10 CFR 63.111(b)(2) [DIRS 156605], the Category 2 performance objectives, reassign one or more DBGM-1 SSCs to DBGM-2 until the aggregated dose complies with 10 CFR 63.111(b)(2) [DIRS 156605]. At the completion of the preclosure seismic analysis, the SSCs ITS will be assigned a DBGM category that will be reflected in the 10 CFR 63.2 [DIRS 156605] design bases.

As discussed in Section 3.4, mean annual probabilities of exceedance associated with the DBGM levels are comparable to the design bases levels for SSCs of other nuclear facilities having similar risk significance. To further ensure adequate seismic safety, DOE will implement NRC's seismic design procedures and acceptance criteria for nuclear power plant design, as discussed in Section 3.2. These criteria and procedures are considered conservative for the Yucca Mountain facility SSCs.

\subsection{DESIGN PROCEDURES AND ACCEPTANCE CRITERIA: NUREG-0800}

NUREG-0800 (NRC 1987 [DIRS 103124]), in general, assures the quality and uniformity of NRC staff review and, in some cases, complements regulatory guides by providing a basis acceptable to the staff that may be used to implement requirements of NRC's regulations. In particular, NUREG-0800 identifies the regulations that are applicable to the seismic design of nuclear power reactors and identifies specific acceptance criteria, regulatory guides, and industry standards that provide information, recommendations, and guidance for compliance. The DOE considers that specific acceptance criteria and guidance provided by NUREG-0800 are appropriate for use in preclosure seismic design. These are identified next.

With exceptions as noted below, the DOE considers that Standard Review Plans 3.7.1, Seismic Design Parameters; 3.7.2, Seismic System Analysis; 3.7.3, Seismic Subsystem Analysis; and 3.10, Seismic and Dynamic Qualification of Mechanical and Electrical Equipment in NRC (1987 [DIRS 103124]) provide appropriate acceptance criteria for the preclosure vibratory ground motions design of repository surface facilities that are ITS. The exceptions are as follows:

- Where differentiated in NUREG-0800, requirements for documentation to be provided in the preliminary safety analysis report to support an application for the construction permit are appropriate for the mined geologic repository system LA for construction authorization; whereas, requirements for documentation to be included in the final safety analysis report to support an application for an operating license, are not appropriate for the mined geologic repository system LA for construction authorization. 
- Requirements for the design of those specific SSCs that are present in a nuclear power reactor, but which would not be present in repository surface facilities, do not apply.

- Requirements for analyses of reactor-specific accident scenarios, such as a loss-of-coolant accident, do not apply.

- In general, the requirements of 10 CFR Part 100, Appendix A, for development of design basis ground motions do not apply. In particular, requirements for the operating basis earthquake and safe shutdown earthquake ground motions do not apply. The DOE will develop design basis ground motions DBGM-1 and DBGM-2 as discussed in Section 3.1.

- Regulatory Guide 1.60 (1973 [DIRS 151402]) design response spectra will not be used. Site-specific, smooth design response spectra will be developed following the procedures outlined in Regulatory Guide 1.165.

- References to “seismic Category-1" SSCs, per NUREG-0800 terminology, will be treated as references to SSCs ITS, in accordance with the definition of this term in 10 CFR Part 63 [DIRS 156605].

Acceptance Criteria from other standard review plans in Chapter 3, Design of Structures, Components, Equipment and Systems (e.g., 3.8.4, Other Seismic Category 1 Structures; 3.9.1, Special Topics for Mechanical Components; and 3.11, Environmental Design of Category 1 Mechanical and Electrical Equipment), will be evaluated for applicability to the repository surface and subsurface facilities.

The DOE also reviewed SECY-93-087, Policy, Technical, and Licensing Issues Pertaining to Evolutionary and Advanced Light-Water Reactor (ALWR) Designs (Taylor 1993 [DIRS 165664]) for potential use in repository seismic design. NRC regulations that govern the seismic design of existing nuclear power reactors (10 CFR Part 100, Appendix A) require that safety-related SSCs be designed for an operating basis earthquake (OBE) as well as the safe shutdown earthquake. The OBE is that earthquake that could reasonably be expected to affect the plant site during the operating life of the plant and that produces the vibratory ground motion for which safety-related SSCs are designed to remain functional. In the NRC regulations that apply to the seismic design of future power reactors (10 CFR Part 100, Subpart B), the requirement to design for an OBE in addition to the SSE has been eliminated; the OBE remains as a shutdown-and-inspection threshold). In Section 1(M) of SECY-93-087 (Taylor 1993 [DIRS 165664]), NRC staff provides guidance to fill several gaps in regulatory guidance that were created by the elimination of the OBE as a design-basis earthquake. This guidance potentially is applicable to repository seismic design because repository SSCs that are ITS will have a single design basis earthquake ground motion (DBGM-1 level or DBGM-2 level, as appropriate).

The DOE anticipates taking no exceptions to the NRC staff guidance in SECY-93-087 (Taylor 1993 [DIRS 165664]) regarding the analysis of piping system fatigue, the effects of 
relative seismic anchor motion in piping systems, and the seismic qualification of equipment ${ }^{2}$. DOE's acceptance of the SECY-93-087 guidance will be re-examined when the DBGM-1 and -2 level design basis ground motions are finalized and when detailed design is performed. If a need for an exception is identified, the DOE will notify NRC staff and request staff review and concurrence.

\subsection{SEISMIC MARGIN EVALUATION}

To ensure that the combination of design basis ground motions and design procedures are adequately conservative, analyses will be conducted that demonstrate adequate seismic margins and, through the PCSA, compliance with the preclosure performance objectives of 10 CFR 63.111 [DIRS 156605]. The approaches and analyses that will be undertaken to demonstrate adequate seismic margin have precedence in the design evaluations that have been conducted to evaluate the seismic margins of nuclear facilities, for example the NRC's Individual Plant Examination of External Events program (Chen et al. 1991 [DIRS 162002]). The analyses are summarized in Sections 3.3.1 and 3.3.2, and are described in detail in Appendices A and B.

\subsubsection{Beyond-Design Basis Ground Motions Analysis}

Structural analyses will be conducted for SSCs ITS at "beyond design basis ground motion" levels to demonstrate the capacity of the SSCs ITS to perform their intended safety functions at ground motion levels that are larger than the design basis ground motions. SSCs ITS designed to the DBGM-2 level (5 $\times 10^{-4}$ annual probability of exceedance) will be evaluated for beyonddesign basis ground motions (BDBGM) at the $1 \times 10^{-4}$ annual probability of exceedance. A stepwise process will be followed in which the BDBGM will provide the input to seismic demand analyses and these demands will be compared with progressively more realistic strength capacities (Appendix A). In steps 1 through 3 given in Appendix A, linear elastic demand analyses will be conducted and, if necessary, step 4 would involve non-linear evaluation of the SSC to compare the seismic demands to high confidence strength capacities. If seismic demands exceed the strength capacities in all four steps, the applicable SSC will be redesigned and reevaluated to ensure adequate seismic margin. Appendix A provides a detailed discussion of the approach to be followed.

\subsubsection{HCLPF Seismic Margin Analysis}

In addition to the beyond-design basis structural analyses, HCLPF seismic margins analyses will demonstrate that SSCs ITS designed to DBGM-2 have adequate seismic margins to ensure that seismically-initiated event sequences will meet the preclosure performance objectives. The methodology for developing HCLPF values for particular SSCs is given in Appendix B. The HCLPF seismic margins analyses will provide direct input to the PCSA, where the compliance demonstration of seismically-initiated event sequences will be carried out. The approach to evaluate SSCs ITS in seismically-initiated event sequences is demonstrated in analyses that support the LA submittal. This type of analysis has precedent in the seismic margin method

\footnotetext{
${ }^{2}$ The guidance in SECY-93-087 regarding criteria for postulating pipe ruptures and leakage cracks in high- and moderate-energy piping systems does not appear to be applicable because no such systems ITS have, as yet, been identified in the repository design.
} 
endorsed by the NRC as an acceptable method for seismic margin analysis as part of the Individual Plant Examination of External Events program (Chen et al. 1991 [DIRS 162002]).

The HCLPF capacity, which is defined as the ground motion level at which there is a mean conditional probability of failure of 0.01 or less, will be calculated for each SSC in the event sequence. For SSCs ITS designed to DBGM-2, the HCLPF capacity will be compared with the ground motions associated with annual probabilities of exceedance of $1 \times 10^{-4}$ to demonstrate acceptable performance at these BDBGM levels. As defined for this analysis, the "HCLPF seismic margin" for each of these SSCs will be computed as the ratio of the HCLPF seismic capacity to the $1 \times 10^{-4} / \mathrm{yr}$ exceedance-frequency ground motion level, and will be reported. To be acceptable, the HCLPF seismic margin should be greater than 1.0 and a target minimum value of 1.10 is deemed acceptable for these SSCs. It is recognized that the 0.01 probability of failure at the HCLPF capacity for a $1 \times 10^{-4} / \mathrm{yr}$ exceedance-frequency does not translate into a probability less than $10^{-6}$ for Category 2 events. However, this seismic margin will ensure that there is essentially zero chance of failure at the design basis ground motion levels and that there is significant margin at the BDBGM level. If the HCLPF capacity does not exceed the $1 \times 10^{-4}$ ground motion level, the SSC will be redesigned to a higher level of ground motion such that there will be acceptable performance at the $1 \times 10^{-4}$ ground motion level.

Because the BDBGM level of $1 \times 10^{-4}$ is comparable to the accepted design bases for nuclear power plants, and because the DOE will demonstrate safe performance at this level and considerable margin beyond this level following approaches that have well-established nuclear precedents, it is reasonable in the context of the concepts described in Section 63.102 [DIRS 156605] to consider initiating events with annual probabilities of exceedance of $1 \times 10^{-4}$ or higher in the PCSA for determining event sequences. It is anticipated that SSCs ITS for which acceptable performance has been demonstrated at the $1 \times 10^{-4}$ level will have HCLPF capacities that substantially exceed the $1 \times 10^{-4}$ ground motion levels. Demonstrating this will ensure that there is significant margin against unacceptable performance at the $1 \times 10^{-4}$ annual probability level and essentially zero chance of failure at the design basis ground motion level.

The DOE considers that the approach outlined above is consistent with precedents adopted for nuclear facilities with comparable or higher risks to workers and the public and that it meets the regulatory intent of the concepts described in Section 63.102 [DIRS 156605] and the preclosure performance objectives established in Section 63.111 [DIRS 156605].

\subsection{COMPARISON WITH OTHER SEISMIC DESIGN BASES}

As noted in Section 3, acceptable seismic safety is achieved through a combination of two important design aspects: (1) the DBGM hazard level, and (2) the conservatism in the design procedures, acceptance criteria, codes, and standards. Therefore, the seismic design criteria given in this topical report can be compared with those for other facilities in two ways: (1) the design basis ground motion hazard levels, and (2) the amount of seismic margin due to design procedures, acceptance criteria, codes, and standards. Comparison of the DBGM hazard levels given in this report, as well as the seismic margin, shows that consistent with a risk-informed approach, the proposed DBGM levels and design criteria and procedures are reasonable and appropriate relative to other facilities having comparable or greater levels of risk. Table 2 
compares the design basis mean annual probabilities of exceedance for facilities ranging from nuclear power plants to essential buildings. As discussed in Section 2.3, the DBGM-1 and DBGM-2 levels are comparable to the reference probability levels for comparable facilities. Nuclear power reactors have higher risk significance than the preclosure facilities at Yucca Mountain due to their high operating pressures and temperatures, and the consequent high potential for dispersion of radionuclides. Many of the preclosure facilities are comparable to those classified as Performance Category PC-3 or PC-2 facilities using the definitions in DOE-STD-1020-2002 (2002 [DIRS 159258]).

The risk-reduction ratio $\left(R_{R}\right)$ is a measure of the seismic margin with respect to failure due to design procedures, acceptance criteria, codes, and standards. In the context of this report, the $R_{R}$ is the ratio of the DBGM annual probability of exceedance and the mean annual probability of failure at that DBGM (where "failure" is defined as loss of intended function). As described in testimony (NRC 2002 [DIRS 161325], pp. 16 to 19), $R_{R}$ is the design margin and is a function of the conservatism in design procedures, acceptance criteria, codes, and standards. The proposed design procedures, acceptance criteria, codes, and standards in this report are those associated with applicable parts of the Standard Review Plan (NRC 1987 [DIRS 103124]) and will include high levels of conservatism. The conservative design procedures, acceptance criteria, codes, and standards of the Standard Review plan results in a $R_{R}$ of approximately 10 (NRC 2002 [DIRS 161325], pp. 16 to 19).

The failure probability is calculated by dividing the DBGM probability by $\mathrm{R}_{\mathrm{R}}$; and therefore, the failure probability is directly related to the annual ground motion exceedance probability and the $\mathrm{R}_{\mathrm{R}}$. For most SSCs, the loss of intended function will not necessarily lead directly to a dose consequence and should not be interpreted as the probability of some level of dose. Therefore, the failure probabilities shown in Table 2 are upper limits to, and likely significantly higher than, the probability of significant doses. However, they provide a common basis for comparison of the expected consequences of the combination of the two important aspects of seismic design: (1) design basis ground motion probability levels, and (2) conservatism in design procedures, acceptance criteria, codes, and standards.

The comparison in Table 2 shows that the proposed risk-informed approach for determination of seismic DBGM, together with conservative design procedures and acceptance criteria, will lead to failure probabilities that are comparable to those for similar facilities. 
Table 2. Comparison of Seismic Design Bases, Risk Reduction Ratios, and Failure Probabilities

\begin{tabular}{|c|c|c|c|}
\hline $\begin{array}{c}\text { YMP Design Basis Ground } \\
\text { Motion (DBGM) Levels vs. Other } \\
\text { Facility Design Levels }\end{array}$ & $\begin{array}{l}\text { DBGM Mean Annual } \\
\text { Exceedance Probability } \\
\text { (return period) }\end{array}$ & $\begin{array}{l}\mathbf{R}_{\mathbf{R}} \text {, Risk } \\
\text { Reduction } \\
\text { Ratio }^{\mathrm{a}}\end{array}$ & $\begin{array}{l}\text { Mean Annual } \\
\text { Probability of } \\
\text { Failure }^{\mathrm{b}} \\
\text { (chance/yr) }^{\mathrm{c}}\end{array}$ \\
\hline New nuclear power plants & $\sim 1 \times 10^{-4}(10,000 \mathrm{yr})^{\mathrm{d}}$ & $\sim 10(5$ to $>20)$ & $\begin{array}{c}\sim 1 \times 10^{-5} \\
(1: 100,000)\end{array}$ \\
\hline $\begin{array}{l}\text { DOE-STD-1020-2002: } \\
\text { Performance Category PC4 } \\
\text { (operating reactors) }\end{array}$ & $1 \times 10^{-4}(10,000 \mathrm{yr})$ & 10 & $\begin{array}{c}1 \times 10^{-5} \\
(1: 100,000)\end{array}$ \\
\hline$Y M P D B G M-2$ & $5 \times 10^{-4}(2,000 \mathrm{yr})$ & $\sim 10(5$ to $>20)$ & $\begin{array}{c}\sim 5 \times 10^{-5} \\
(1: 20,000)\end{array}$ \\
\hline $\begin{array}{l}\text { Private Fuel Storage (Independent } \\
\text { Spent Fuel Storage Facility) }\end{array}$ & $5 \times 10^{-4}(2,000 \mathrm{yr})$ & $\geq 5$ & $\begin{array}{c}\leq 1 \times 10^{-4} \\
(\geq 1: 10,000)\end{array}$ \\
\hline $\begin{array}{l}\text { DOE-STD-1020-2002: } \\
\text { Performance Category PC3 (non- } \\
\text { reactor nuclear facilities) }\end{array}$ & $5 \times 10^{-4}(2,000 \mathrm{yr})^{\mathrm{e}}$ & 5 & $\begin{array}{c}1 \times 10^{-4} \\
(1: 10,000)\end{array}$ \\
\hline YMP DBGM-1 & $1 \times 10^{-3}(1,000 \mathrm{yr})$ & $\sim 10$ (5 to >20) & $\begin{array}{c}1 \times 10^{-4} \\
(1: 10,000) \\
\end{array}$ \\
\hline $\begin{array}{l}\text { DOE-STD-1020-2002: } \\
\text { Performance Category PC2 } \\
\text { (essential buildings) }\end{array}$ & [see IBC-2000] & & \\
\hline International Building Code- $2000^{g}$ & $\begin{array}{c}7 \times 10^{-4}-4.7 \times 10^{-4} \\
(1430-2145 \mathrm{yr})^{f}\end{array}$ & $\sim 0.7-0.5$ & $\begin{array}{c}1 \times 10^{-3} \\
(1: 1,000)\end{array}$ \\
\hline
\end{tabular}

Sources:

DOE-STD-1020-2002, Section 2.2 (DOE 2002 [DIRS 159258]; International Building Code 2000 (ICC (International Code Council) 2000 [DIRS 159179], Section 1615); McGuire, et al. 2001 [DIRS 157510], Section 7.3.3; NRC 2002 [DIRS 161325], pp. 15 through 19; Travers 2003 [DIRS 165666] Attachment 4; Regulatory Guide 1.1651997 [DIRS 119139], Appendices B and C

NOTES:

a Ratio of DBGM exceedance probability to failure probability, $R_{R}$, is termed "risk reduction ratio." $R_{R}$ is function of design margin due to design procedures, acceptance criteria, codes, and standards.

b "Failure" is defined as the loss of intended function. The conditional probability of having dose consequences, given the seismically induced loss of intended function, must be assessed separately.

c In some cases, these probabilities represent performance goals, such as those described in DOE-STD-1020-2002. In other cases, they are implicit goals and are calculated based on estimates of $R_{R}$ and the DBGM exceedance probability. They provide a generalized basis for comparison.

${ }^{\mathrm{d}}$ Regulatory Guide 1.165 specifies using a median hazard level of $1 \times 10^{-5}$ for design; this corresponds approximately with a mean hazard level of $1 \times 10^{-4}$.

e Assuming a site away from tectonic plate boundaries, the design seismic hazard exceedance is $4 \times 10^{-4}$ (2500-years return period). Design forces are multiplied by a Scale Factor of 0.9 to bring the earthquake design levels to approximately 2000-year return period.

$f$ Assuming a site away from tectonic plate boundaries and range of Seismic Factor from 1.0 to 1.5.

g 1430 is lower bound and 2145 is upper bound, which is 1.5 times 1430, as per Travers 2003 [DIRS 165666] Attachment 4, p. 11.

The symbol " " is used to indicate approximately. 


\section{MITIGATION OF FAULT DISPLACEMENT HAZARDS}

This section describes the methods, procedures, and criteria that DOE intends to use to provide reasonable assurance that SSCs ITS will meet the pertinent 10 CFR Part 63 [DIRS 156605] preclosure performance objectives with respect to fault displacement. The primary design approach for fault displacement is to locate (whenever feasible) SSCs ITS away from Quaternary faults with a potential for significant displacement so that no explicit fault displacement design is required. NUREG-1451 (McConnell et al. 1992, Section 3.1.3 [DIRS 105205]) defines 'Type I' faults as faults or fault zones that are subject to displacement and that may affect repository design and/or performance. This definition includes two components: (1)“subject to displacement" implies that the fault is a Quaternary fault, and (2) "may affect the design and/or performance" implies that an evaluation has been made of design and/or performance significance. Without a priori knowledge of design and/or performance significance, one cannot indicate which faults are Type I and which are not. As a result, the terminology "Quaternary fault with potential for significant displacement" is used in this document to indicate those faults that may potentially be Type I faults.

As discussed below in Section 4.2, for those SSCs (if any) that must consider fault displacement, the design basis fault displacement hazards shall be a factor of ten lower MAPE than those for ground motions. A description is given of the approach to determining design basis fault displacements and the fault-displacement design acceptance criteria.

\subsection{CRITERIA FOR FAULT AVOIDANCE}

Unlike vibratory ground motion hazard, fault displacement hazard is concentrated at the location of faults. Consequently, the exposure of SSCs to fault displacement hazard can be limited by avoiding the locations of faults that have a significant potential for fault displacement. Fault avoidance is the DOE's preferred approach to mitigating fault hazards. Whether the potential for fault displacement is significant depends on the SSC in question. The hazard is judged to be significant when it is such that an explicit fault displacement design might be necessary to accommodate the hazard. Conversely, the hazard is judged to be negligible-and fault avoidance is deemed to have been achieved-when the hazard is so low that there clearly is no need for the SSC in question to have an explicit fault displacement design.

Given the variability and uncertainties regarding the size and recurrence rate of displacement episodes on local faults, fault displacement hazard is best assessed probabilistically, and design basis fault displacements are best assessed probabilistically. To account for the uncertainties and acknowledging less experience in seismic design for displacement than for vibratory ground motions, the reference design probability levels are one order of magnitude lower than for ground motions. The MAPE is $1 \times 10^{-4}$ for design basis fault displacement DBFD-1 and $5 \times 10^{-5}$ for design basis fault displacement DBFD-2. The DOE's criteria for fault avoidance are consistent with these exceedance probabilities. Specifically, the DOE will assess the probabilistic fault displacement hazard for each SSC ITS, identify the fault displacement that corresponds to the applicable DBFD level, and judge whether, for that displacement level, an explicit fault displacement design would be necessary. If the level is low enough that an explicit 
fault displacement design clearly is not necessary, fault avoidance will be deemed to have been achieved.

The DOE expects that fault avoidance can be achieved for all ITS surface and subsurface SSCs that are spatially compact. Fault avoidance may or may not be feasible for all subsurface SSCs that are spatially extended. In any case, if fault avoidance is not feasible for any SSC that is ITS, it will be designed to accommodate the applicable design basis fault displacement without loss of safety function.

As an approach to fault avoidance, the DOE could establish minimum fault standoff or setback distances. A minimum fault setback distance would establish the fault distance beyond which a SSC could be located without needing an explicit fault displacement design. The establishment of a setback distance would require the evaluation of fault displacement hazard as a function of distance from local faults and the determination of threshold displacement levels for each SSC in question, above which explicit fault displacement design would be required (setback distances would, thus, be both fault- and SSC-specific). However, the DOE now considers that the identification of minimum fault setback distances likely will not be necessary. Repository design has advanced to the point where the general locations of proposed surface waste handling facilities and subsurface waste emplacement areas are known, and the DOE expects that the displacement hazard estimate at these locations will be so low that it will be obvious that there is no need for explicit fault displacement designs. Assuming this proves to be the case, it will not be necessary to determine how close SSCs could be placed to local Quaternary faults before an explicit fault displacement design would be required.

It is possible that spatially extended SSCs that cross Quaternary faults with potential for significant fault displacement will be classified as ITS. If this is the case, the DOE will use the probabilistic fault displacement hazard analysis (CRWMS M\&O 1998 [DIRS 103731]), identify the fault displacement that corresponds to the applicable DBFD-1 or DBFD-2 MAPE at the particular location of the SSC, and determine whether an explicit fault displacement design is necessary to accommodate the potential displacement with high confidence. If a fault displacement design is required, it will be executed per the acceptance criteria described in Section 4.2.2.

\subsubsection{Implementation of NRC Staff Technical Position on Consideration of Fault Displacement Hazards in Geologic Repository Design}

The NRC staff's position on the consideration of fault displacement hazards in geologic repository design is published in NUREG-1494 (McConnell and Lee 1994, Section 3 [DIRS 110957]). NUREG-1494 states that "in general, areas within the controlled area of a geologic repository that contain 'Type I' faults should be avoided, where this can be reasonably achieved, when locating structures, systems, and components ITS or important to waste isolation." As described in Section 4.1 of this report, the DOE's approach to fault avoidance is, where feasible, to locate SSCs that are ITS at locations where the fault displacement hazard is so low that clearly no explicit fault displacement design is required. This approach inherently avoids Quaternary faults with potential for significant displacement and is consistent with the staff's guidance in NUREG-1451. 
The assessment of fault displacement (and vibratory ground motion) hazards at the site was conducted using the methodology described in the first seismic topical report (YMP 1997 [DIRS 100522]) and is documented in CRWMS M\&O (1998 [DIRS 103731]). To support the seismic hazard assessment, the DOE has mapped in detail the faults at and near the site and has investigated all known and suspected Quaternary faults in the Yucca Mountain region that are of sufficient length and located such that they could materially contribute to the vibratory ground motion or fault displacement hazard at the site. The DOE expects that the level of detail in the fault investigations and the area investigated has been sufficient to identify all Quaternary faults with potential for significant displacement that could impact preclosure repository design. The probabilistic fault displacement hazard analysis (CRWMS M\&O 1998 [DIRS 103731]) will be used to calculate the amount of fault displacement associated with the DBFD-1 and DBFD-2 annual probability levels at any particular SSC location within the geologic repository operations area.

\subsection{CRITERIA FOR FAULT DISPLACEMENT DESIGN}

\subsubsection{Determination of Design Basis Fault Displacements}

When fault avoidance is not feasible for SSCs ITS, these SSCs will be designed to withstand the design basis fault displacement without loss of their required safety functions. The DOE considers that probabilistic criteria for design basis fault displacements are most appropriate to implement a risk-informed design process. Specifically, the DOE considers that fault displacements having mean annual exceedance probabilities of $1 \times 10^{-4}$ and $5 \times 10^{-5}$ are appropriate for DBFD-1 and DBFD-2, respectively. These values are a factor of 10 lower than the exceedance probabilities of the corresponding DBGM-1 and DBGM-2 reflecting the more limited experience with engineering design of facilities for fault displacement and with assessments of fault displacement hazard.

The motivation and justification for using a probabilistic rather than deterministic description of design basis fault displacements are the same as for design basis vibratory ground motions. Specifically, the advantages are that a properly done probabilistic fault hazard analysis captures and reflects both the variability and uncertainty, and accounts for both the magnitude and the likelihood of occurrence of the hazard. Therefore, a probabilistic approach provides the information that is needed to implement a risk-informed design methodology, plus it provides the type of information that is needed for the PCSA in order to evaluate compliance with the preclosure performance objectives.

\subsubsection{Acceptance Criteria for Fault Displacement Design}

Fault displacement loads depend on the magnitude and direction of the fault movement and on the ease with which the two segments of the SSC on two sides of the fault can move relative to each other. The latter depends on the following:

- The stiffness (or flexibility) of the SSC, especially in the vicinity of the fault

- The stiffness (or flexibility) of the ground around the buried segment or foundation of the SSC, especially in the vicinity of the fault 
- The configuration of the SSC.

Once the design basis fault displacements are determined, the resulting loads (or stresses) and deformations (or strains) in the SSC will be calculated using analytical models that will consider the above three parameters. When similar loads/stresses and deformations/strains are calculated for vibratory ground motion, it is customary to use stress-based acceptance criteria to establish design adequacy assuming essentially linear elastic behavior, which is the basis for industry codes and standards. Unlike vibratory ground motion loads, however, fault displacement loads are generally localized and often cause inelastic response of SSCs, unless the SSC and the ground medium are very flexible, in which case the SSC can undergo large deformation and stay within elastic limits. For this reason, the DOE intends to use strain-based acceptance criteria to establish the design adequacy of SSCs subjected to fault displacement loads.

In establishing strain-based acceptance criteria for the Yucca Mountain repository facilities, nuclear power plant and industry experiences with the use of strain-based criteria will be used. Examples are the strain criteria used for designing pipe rupture restraint systems and for designing SSCs subject to accidental impact and impulse loads such as those resulting from tornado missiles, turbine missiles, aircraft crashes, cask drops, reactor vessel head drops, and others that may be applicable. Some similarities also exist between localized inelastic response of SSCs when subject to fault loads and localized stress well beyond linear elastic limit of materials. Because of uncertainties in the fragilities of SSCs however, the design acceptance criteria for fault displacement loads will not permit strain levels up to the ultimate or failure strain limit of the material. Instead, the limiting strain will be determined by considering the parameters that influence the fragility of the SSC. Explicitly, these are the configuration of the SSC, the SSC failure mode, the SSC material characteristics (brittle versus ductile), the stiffness of the SSC, and the stiffness of the ground material in the vicinity of the fault. Considering these parameters, strain limits will be established on a case-by-case basis to provide reasonable assurance that the seismic safety goal established for the SSC will be achieved.

In addition to imposing strain-based acceptance criteria when an explicit fault displacement design is required, the DOE will follow conservative layout guidelines when locating ITS SSCs relative to Quaternary faults with potential for significant displacement. For instance, when practical layout requirements make it necessary to place spatially extended SSCs across a Quaternary fault with potential for significant displacement, the layout will be configured such that the SSC crosses the fault trace at a steep angle, minimizing the exposure of the SSC to faulting-induced damage.

\section{SUMMARY}

This topical report describes the methodology and criteria that the DOE intends to use for preclosure seismic design of SSCs that are ITS and credited with preventing the initiation of, or mitigating the consequences of a seismically initiated event sequence in the geologic repository operations area. This report is the second of two topical reports on seismic hazards and preclosure seismic design of the repository at Yucca Mountain, Nevada. The implementation of the methodologies in the topical reports is documented in Development of Earthquake Ground Motion Input for Preclosure Seismic Design and Postclosure Performance Assessment of a 
Geologic Repository at Yucca Mountain, NV (BSC 2004 [DIRS 168780]). These documents together constitute supporting technical documentation for satisfying the NRC's regulatory requirements with respect to ground motion and fault displacement inputs for preclosure design and postclosure performance assessment of the repository at Yucca Mountain.

This revision to the topical report supercedes Revision 2 (YMP 1997 [DIRS 100521]) and has been updated to include appropriate reference to 10 CFR Part 63, rather than 10 CFR Part 60, as well as the recently finalized Yucca Mountain Review Plan (NRC 2003 [DIRS 163274]). In addition, this revision reflects consideration of recent seismic design experience and regulatory decision-making that has occurred during the past several years. These activities provide a context and precedence for the seismic design methodologies put forward in this document.

The establishment of preclosure seismic design criteria involves both PCSA as well as repository design. Evaluations of preclosure safety are made with respect to a reference design for the geologic repository operations area. Therefore, the fundamental SSCs of the preclosure design are evaluated in the PCSA to identify those SSCs that are ITS, per the definition given in Section 63.2 [DIRS 156605]. This report provides a risk-informed methodology for assigning seismic design basis ground motions to those SSCs that have been determined to be ITS and credited with preventing the initiation of, or mitigating the consequences of, a seismically initiated event sequence. The risk information that is used to assign the level of design basis ground motions comes from the PCSA.

Acceptable seismic safety is achieved through a combination of two important design aspects: (1) the DBGM level, and (2) the conservatism in the design procedures, acceptance criteria, codes, and standards. Per regulation, DOE is free to choose whatever seismic design bases and design procedures it feels will provide reasonable assurance that the preclosure performance objectives of 10 CFR Part 63 [DIRS 156605] are met. The use of appropriate levels of DBGMs coupled with the adoption of the nuclear-power plant seismic design procedures, acceptance criteria, codes, and standards in NUREG-0800 (NRC 1987 [DIRS 103124] are part of the design methodology described in this topical report. Ultimately, evaluations as part of the PCSA will demonstrate compliance to the dose standards in 10 CFR 63.111 [DIRS 156605].

Two design basis ground motion (DBGM) levels will be used for the seismic design of structures, systems, and components ITS:

- DBGM-1 having a MAPE of $1 \times 10^{-3}$ (1,000 year return period)

- DBGM-2 having a MAPE of $5 \times 10^{-4}$ (2,000 year return period).

The determination of appropriate DBGM levels for specific SSCs depends on their risk significance, as evaluated in the PCSA

NUREG-0800 (NRC 1987 [DIRS 103124]) identifies the regulations that are applicable to the seismic design of nuclear power reactors and identifies specific acceptance criteria, regulatory guides, and industry standards that provide information, recommendations, and guidance for compliance. With the exceptions identified in this document, the DOE considers that specific acceptance criteria and guidance provided by NUREG-0800 are appropriate for use in preclosure seismic design. 
To ensure that the combination of design basis ground motions and design procedures are adequately conservative, structural analyses will be conducted that demonstrate adequate seismic margins and, through the PCSA, assure the preclosure performance objectives of 10 CFR 63.111 [DIRS 156605] are met. Structural analyses will be conducted for SSCs ITS at "beyond design basis ground motion" levels to demonstrate the capacity of the SSCs to perform their intended safety functions at ground motion levels that are larger than the design basis ground motions. SSCs designed to the DBGM-2 level $\left(5 \times 10^{-4}\right.$ annual probability of exceedance $)$ will be evaluated for beyond-design basis ground motions (BDBGM) at the $1 \times 10^{-4}$ annual probability of exceedance. In addition to the beyond-design basis structural analyses, HCLPF seismic margins analyses will demonstrate that SSCs ITS designed DBGM-2 have adequate seismic margins to ensure that seismically-initiated event sequences will meet the preclosure performance objectives.

This document describes the methods, procedures, and criteria that DOE intends to use to provide reasonable assurance that SSCs ITS will meet the pertinent 10 CFR Part 63 [DIRS 156605] preclosure performance objectives with respect to fault displacement. The primary design approach for fault displacement is to locate (whenever feasible) SSCs ITS away from Quaternary faults with potential for significant displacement so that no explicit fault displacement design is required. However, for those SSCs (if any) that must consider fault displacement, the design basis fault displacement hazards shall be a factor of ten lower MAPE than those for ground motions.

\section{REFERENCES}

\subsection{DOCUMENTS CITED}

159618 ASCE 4-98 (American Society of Civil Engineers). 2000. Seismic Analysis of Safety-Related Nuclear Structures and Commentary. Reston, Virginia: American Society of Civil Engineers. TIC: 253158.

168780 BSC (Bechtel SAIC Company) 2004. Development of Earthquake Ground Motion Input for Preclosure Seismic Design and Postclosure Performance Assessment of a Geologic Repository at Yucca Mountain, NV. MDL-MGR-GS-000003 REV 00 [Errata 001]. Las Vegas, Nevada: Bechtel SAIC Company. ACC: DOC.20031201.0001; DOC.20040401.0004.

168030 BSC (Bechtel SAIC Company) 2004. Characterize Framework for Seismicity and Structural Deformation at Yucca Mountain, Nevada. ANL-CRW-GS-000003 REV 00 [Errata 001]. Las Vegas, Nevada: Bechtel SAIC Company. ACC: MOL.20000510.0175; DOC.20040223.0007.

167780 BSC (Bechtel SAIC Company) 2004. Seismic Consequence Abstraction. MDL-WISPA-000003 REV 0 Errata 1. Las Vegas, Nevada: Bechtel SAIC Company. ACC: DOC.20030818.0006; DOC.20040218.0002. 
165660 Budnitz, R.J.; Amico, P.J.; Cornell, C.A.; Hall, W.J.; Kennedy, R.P.; Reed, J.W.; and Shinozuka, M. 1985. An Approach to the Quantification of Seismic Margins in Nuclear Power Plants. NUREG/CR-4334. (UCID-20444). Washington, D.C.: U.S. Nuclear Regulatory Commission. TIC: 254460.

162002 Chen, J.T.; Chokshi, N.C.; Kenneally, R.M.; Kelly, G.B.; Beckner, W.D.; McCracken, C.; Murphy, A.J.; Reiter, L.; and Jeng, D. 1991. Procedural and Submittal Guidance for the Individual Plant Examination of External Events (IPEEE) for Severe Accident Vulnerabilities. NUREG-1407. Washington, D.C.: U.S. Nuclear Regulatory Commission. TIC: 237269.

103731 CRWMS M\&O (Civilian Radioactive Waste Management System, Management and Operating Contractor) 1998. Probabilistic Seismic Hazard Analyses for Fault Displacement and Vibratory Ground Motion at Yucca Mountain, Nevada. Milestone SP32IM3, September 23, 1998. Three volumes. Las Vegas, Nevada: CRWMS M\&O. ACC: MOL.19981207.0393.

161324 DOE-STD-1020-94. 1994. Natural Phenomena Hazards Design and Evaluation Criteria for Department of Energy Facilities. Washington, D.C.: U.S. Department of Energy. TIC: 211288.

159258 DOE-STD-1020-2002. 2002. Natural Phenomena Hazards Design and Evaluation Criteria for Department of Energy Facilities. Washington, D.C.: U.S. Department of Energy. TIC: 253058.

161328 Duffey, T.A.; Goldman, A.; and Farrar, C.R. 1994. Shear Wall Ultimate Drift Limits. NUREG/CR-6104. Washington, D.C.: U.S. Nuclear Regulatory Commission. TIC: 253769.

161330 EPRI (Electric Power Research Institute) 1991. A Methodology for Assessment of Nuclear Power Plant Seismic Margin (Revision 1). EPRI NP-6041-SL, Rev. 1. Palo Alto, California: Electric Power Research Institute. TIC: 253771.

165662 Idaho Spent Fuel Facility. [2001]. Safety Analysis Report, Idaho Spent Fuel Facility. ISF-FW-RPT-0033, Rev. 0. Docket Number 72-25. Volume 1. 1.1-1 through 2.6.13. [Livingston, New Jersey]: Foster Wheeler Environmental Corporation.

ACC: MOL.20031016.0006.

165661 Ihde, R.H. 2001. “Docket Number 070-03098 Duke Cogema Stone \& Webster Mixed Oxide (MOX) Fuel Fabrication Facility Construction Authorization Request.” Letter from R.H. Ihde (Duke Cogema Stone \& Webster) to W.F. Kane (NRC), February 28, 2001, DCS-NRC-000038, with enclosures.

ACC: MOL.20031016.0005.

161326 Kennedy, R.C. and Short, S.A. 1994. Basis for Seismic Provisions of DOE-STD-1020. UCRL-CR-111478. Livermore, California: Lawrence Livermore National Laboratory. TIC: 223006. 
155940 Kennedy, R.P. 2001. "Overview of Methods for Seismic PRA and Margin Analysis Including Recent Innovations.” Proceedings of the OECD/NEA Workshop on Seismic Risk, Committee on the Safety of Nuclear Installations PWG3 and PWG5, Hosted by the Japan Atomic Energy Research Institute under the Sponsorship of the Science Technology Agency, 10-12 August, 1999, Tokyo, Japan.

NEA/CSNI/R(99)28, 33-63. Paris, France: Organization for Economic Co-operation and Development, Nuclear Energy Agency. TIC: 253825.

110957 McConnell, K.I. and Lee, M.P. 1994. Staff Technical Position on Consideration of Fault Displacement Hazards in Geologic Repository Design. NUREG-1494. Washington, D.C.: U.S. Nuclear Regulatory Commission. TIC: 212360.

105205 McConnell, K.I.; Blackford, M.E.; and Ibrahim, A.B. 1992. Staff Technical Position on Investigations to Identify Fault Displacement Hazards and Seismic Hazards at a Geological Repository. NUREG-1451. Washington, D.C.: U.S. Nuclear Regulatory Commission. TIC: 204829.

157510 McGuire, R.K.; Silva, W.J.; and Costantino, C.J. 2001. Technical Basis for Revision of Regulatory Guidance on Design Ground Motions: Hazard- and Risk-Consistent Ground Motion Spectra Guidelines. NUREG/CR-6728. Washington, D.C.:

U.S. Nuclear Regulatory Commission. TIC: 251294.

103124 NRC (U.S. Nuclear Regulatory Commission) 1987. Standard Review Plan for the Review of Safety Analysis Reports for Nuclear Power Plants. NUREG-0800. LWR Edition. Washington, D.C.: U.S. Nuclear Regulatory Commission. TIC: 203894.

161325 NRC (U.S. Nuclear Regulatory Commission) 2002. Applicant's Preface of the Testimony of C. Allin Cornell on Unified Contention Utah L/QQ, Before the Atomic Safety and Licensing Board, in the Matter of Private Fuel Storage L.L.C. (Private Fuel Storage Facility), April 1, 2002. NRC Docket No. 72-22. [Washington, D.C.]: U.S. Nuclear Regulatory Commission. TIC: 253444.

163274 NRC (U.S. Nuclear Regulatory Commission) 2003. Yucca Mountain Review Plan, Final Report. NUREG-1804, Rev. 2. Washington, D.C.: U.S. Nuclear Regulatory Commission, Office of Nuclear Material Safety and Safeguards. TIC: 254568.

165667 Parkyn, J.D. 1999. “Request for Exemption to 10 CFR 72.102(f)(1), Seismic Design Requirement Docket No. 72-22/TAC NO. L22462, Private Fuel Storage Facility, Private Fuel Storage L.L.C.” Letter from J.D. Parkyn (PFS LLC) to U.S. Nuclear Regulatory Commission, August 24, 1999. MOL.20031016.0011.

151402 Regulatory Guide 1.60, Rev. 1. 1973. Design Response Spectra for Seismic Design of Nuclear Power Plants. [Washington, D.C.]: U.S. Atomic Energy Commission. TIC: $\underline{232770 .}$. 
119139 Regulatory Guide 1.165. 1997. Identification and Characterization of Seismic Sources and Determination of Safe Shutdown Earthquake Ground Motion. Washington, D.C.: U.S. Nuclear Regulatory Commission. Readily available.

165663 Rogers, D.I., Jr. 2001. "Idaho Spent Fuel (ISF) Facility Foster Wheeler Environmental Corporation Application for 10 CFR Part 72 License Docket No. 72.25.” Letter from D.I. Rogers, Jr. (Foster Wheeler Environmental Corporation) to U.S. Nuclear Regulatory Commission, November 19, 2001, FW-NRC-ISF-01-0608, with enclosures. ACC: MOL.20031016.0007.

165664 Taylor, J.M. 1993. "Policy, Technical, and Licensing Issues Pertaining to Evolutionary and Advanced Light-Water Reactor (ALWR) Designs.” Memorandum from J.M. Taylor (NRC) to the Commissioners, April 2, 1993, SECY-93-087, with enclosures. ACC: MOL.20031016.0008.

165666 Travers, W.D. 2003. "Final Rule: Geological and Seismological Characteristics for the Siting and Design of Dry Cask Independent Spent Fuel Storage Installations and Monitored Retrievable Storage Installations - 10 CFR Part 72.” Memorandum from W.D. Travers (NRC) to the Commissioners, July 11, 2003, SECY-03-0118, with attachments. ACC: MOL.20031016.0010.

165665 United States of America Nuclear Regulatory Commission, Atomic Safety and Licensing Board before Administrative Judges: Michael C. Farrar, Chairman, Dr. Jerry R. Kline and Dr. Peter S. Lam, in the Matter of Private Fuel Storage (Independent Spent Fuel Storage), Docket No. 72-22-ISFSI. ASLBP No. 97-732-02-ISFSI. May 22, 2003, Partial Initial Decision (Regarding Geotechnical Issues). ACC: MOL.20031016.0009.

100522 YMP (Yucca Mountain Site Characterization Project) 1997. Methodology to Assess Fault Displacement and Vibratory Ground Motion Hazards at Yucca Mountain. Topical Report YMP/TR-002-NP, Rev. 1. Las Vegas, Nevada: Yucca Mountain Site Characterization Office. ACC: MOL.19971016.0777

100521 YMP (Yucca Mountain Site Characterization Project) 1997. Preclosure Seismic Design Methodology for a Geologic Repository at Yucca Mountain. Topical Report YMP/TR-003-NP, Rev. 2. Las Vegas, Nevada: Yucca Mountain Site Characterization Office. ACC: MOL.19971009.0412.

\subsection{CODES, STANDARDS, REGULATIONS, AND PROCEDURES}

10478710 CFR 20. Energy: Standards for Protection Against Radiation. Readily available.

10354010 CFR 60. Energy: Disposal of High-Level Radioactive Wastes in Geologic Repositories. Readily available.

15660510 CFR 63. Energy: Disposal of High-Level Radioactive Wastes in a Geologic Repository at Yucca Mountain, Nevada. Readily available. 
10354110 CFR 72. Energy: Licensing Requirements for the Independent Storage of Spent Nuclear Fuel and High-Level Radioactive Waste. Readily available.

13059510 CFR 100. Energy: Reactor Site Criteria. Readily available.

15667166 FR 55732. Disposal of High-Level Radioactive Wastes in a Proposed Geologic Repository at Yucca Mountain, NV. Final Rule 10 CFR Part 63. Readily available.

159179 ICC (International Code Council) 2000. International Building Code 2000. Falls Church, Virginia: International Code Council. TIC: 251054. 
APPENDIX A

BEYOND-DESIGN BASIS EARTHQUAKE GROUND MOTIONS ANALYSIS 


\section{INTENTIONALLY LEFT BLANK}




\section{APPENDIX A}

\section{BEYOND-DESIGN BASIS EARTHQUAKE GROUND MOTION ANALYSES}

\section{A-1. OVERVIEW}

This appendix describes the methodology for structural analyses that will be used to demonstrate that SSCs ITS will maintain their intended safety functions when submitted to ground motions that exceed the DBGMs. SSCs designed to the DBGM-2 level $\left(5 \times 10^{-4}\right.$ annual probability of exceedance) will be evaluated for BDBGM at the $1 \times 10^{-4}$ annual probability of exceedance. A stepwise process will be followed in which the BDBGM will provide the input to seismic demand analyses and these demands will be compared with progressively more realistic strength capacities. This appendix describes the approach to be used in these analyses. Because most of the structures ITS are expected to be low-rise concrete shear wall structures, detailed acceptance criteria will be presented for such structures as an example.

Step 1. A linear elastic seismic demand analysis will be performed using the BDBGM as input. This seismic demand analysis will be performed using the same criteria as that used for the DBGM seismic demand analysis, except that the BDBGM will be used as input together with damping consistent with the BDBGM. The computed seismic demands will be compared with the Code capacity acceptance criteria (including Code-specified strength reduction factors $\phi$ ). Note that "Code" in this discussion indicates the Standard Review Plan (NRC 1987 [DIRS 103124]). If the computed BDBGM demands are less than Code capacities, then no further analysis is required. However, if the computed BDBGM demands exceed Code capacities, the exceedance factor will be documented and the analysis will proceed to the second step.

Step 2. In the second step, more realistic (yet still conservative) strength capacities beyond Code capacities will be established if sufficient test data exist to justify such an increase in strength capacities beyond Code capacities. Any strength capacities increased beyond Code capacities will be established at about the 98 percent exceedance probability capacity (2 percent nonexceedance probability capacity, or approximately 2 standard deviations below the mean capacity) in order to have high confidence in these strength capacities. Additional details on criteria to be used in establishing high confidence strength capacities are provided in EPRI (1991 [DIRS 161330], Section 2 and Appendix L), DOE-STD-1020-94 (1994 [DIRS 161324], Section C.5), and Kennedy and Short (1994 [DIRS 161326], Section 4.2). As an example, specific criteria for establishing the high confidence shear strength capacity of low-rise concrete shear walls are given in Section A-2. This specific criterion is taken from EPRI (1991 [DIRS 161330], Appendix L). As an alternative to establishing these more realistic high confidence strength capacities, the Code capacities (including Code specified $\phi$ factors) can continue to be used as the high confidence strength capacities. If the computed BDBGM demands are less than these high confidence capacities, then no further analysis is required and the structure behavior when subjected to the BDBGM will be reported to remain in the essentially elastic range of response. However, if the computed BDBGM demands exceed the high confidence capacities, the analysis will proceed to the third step. 
Step 3. In the third step, the seismic demand/capacity ratio $\left(\mathrm{D}_{S} / \mathrm{C}_{S}\right)$ for the BDBGM will be computed where $\mathrm{D}_{\mathrm{S}}$ is the linear elastic computed seismic demand for the BDBGM, and $\mathrm{C}_{\mathrm{S}}$ is the realistic seismic capacity computed from:

$$
\mathrm{C}_{\mathrm{S}}=\mathrm{C}_{98 \%}-\mathrm{C}_{\mathrm{NS}}
$$

where $\mathrm{C}_{98 \%}$ is the realistic 98 percent exceedance strength capacity computed in Step 2 and $\mathrm{C}_{\mathrm{NS}}$ is the capacity required for non-seismic loads. The computed $\left(\mathrm{D}_{\mathrm{S}} / \mathrm{C}_{\mathrm{S}}\right)$ ratio will be reported and will be compared with the conservative permissible inelastic energy absorption factors $F_{\mu}$ defined in Table 2-4 of DOE (DOE-STD-1020-94 [DIRS 161324]). As an example, the permissible $\mathrm{F}_{\mu}$ for in-plane shear in a concrete shear wall is 1.50 . So long as:

$$
\left(\mathrm{D}_{\mathrm{S}} / \mathrm{C}_{\mathrm{S}}\right) \leq \mathrm{F}_{\mu}
$$

the SSC will be reported to undergo only limited and permissible inelastic behavior when subjected to the BDBGM; therefore, no further analysis is required. If Equation A-2 is not satisfied, the analysis will proceed to the fourth step.

Step 4. In the fourth step, a non-linear evaluation of the structure subjected to the BDBGM input will be performed. The high-confidence strength capacities defined in the second step will be used in this non-linear evaluation. Non-linear distortions (defined in terms of total story drifts per story for concrete shear wall and steel braced frame structures and defined in terms of inelastic hinge rotations and total story drifts for moment frame structures) will be computed and reported.

Total story drift and inelastic hinge rotation limits will be defined in terms of the four limit states qualitatively described in Table A-1. As an example, the allowable total story drift limits for a low-rise concrete shear wall (height to length ratio less than 2.0) are 0.0075, 0.006, and 0.004 for Limit States A, B, and C, respectively (modified from DOE-STD-1020-94 1994 [DIRS 161324], Section 2.3). The basis for these low-rise concrete shear wall drift limits is presented in Section A.3.

Permissible non-linear computed behavior for the BDBGM input will be limited to Limit State C. Limit State C corresponds to high confidence of Limited Permanent Distortion with minimal and easily repairable damage that does not interfere with the ability of the structure to act as a confinement barrier.

As an example, Limit State C limits the lateral drift per story of a low-rise concrete shear wall (height to length ratio less than 2.0) to less than 0.4 percent of the story height. Thus, for a 10 -foot story height, the lateral drift is limited to 0.48-inch. This limit provides high confidence that shear cracks in the wall will be small and that the ultimate strength of the wall will not be reduced by a few cycles of plus and minus distortion carried to this drift limit. The wall retains its full strength and serviceability. This 0.4 percent of the story height drift limit is identical to the drift limit specified in DOE-STD-1020-94 (1994 [DIRS 161324], Section 2.3) for low-rise shear walls. 


\section{A-2. HIGH CONFIDENCE SHEAR STRENGTH CAPACITY OF LOW-RISE CONCRETE SHEAR WALLS}

EPRI (1991 [DIRS 161330], pp. 2-51 to 2-53) recommends that the 98 percent exceedance probability capacity can be estimated by defining material strengths at the 95 percent exceedance probability and capacity equations at the 84 percent exceedance probability. Code-established material strength (i.e., Code-specified yield and ultimate strengths of steel and concrete strength) is specified at about the 95 percent exceedance probability or higher. Therefore, if these Code-specified material strengths are used, it is sufficient to establish the capacity equation at the 84 percent exceedance probability.

EPRI (1991 [DIRS 161330], Appendix L) shows that the nominal (median) ultimate shear strength, $v_{n}$, of a low-rise shear wall with height, $h_{w}$, less than twice its length, $l_{w}$, is given by:

$$
\mathrm{v}_{\mathrm{n}}=8.3 \sqrt{f_{c^{\prime}}}-3.4 \sqrt{f_{c^{\prime}}}\left(\frac{\mathrm{h}_{\mathrm{w}}}{\mathrm{l}_{\mathrm{w}}}-0.5\right)+\frac{\mathrm{N}_{\mathrm{A}}}{4 \mathrm{l}_{\mathrm{w}} \mathrm{t}_{\mathrm{n}}}+\rho_{\mathrm{se}} \mathrm{f}_{\mathrm{y}}
$$

where $f_{\mathrm{c}}{ }^{\prime}$ is the concrete strength, $\mathrm{N}_{\mathrm{A}}$ is the axial load on the wall (compression positive), $\mathrm{t}_{\mathrm{n}}$ is the nominal wall thickness, $\mathrm{f}_{\mathrm{y}}$ is the yield strength of the reinforcing steel and:

$$
\rho_{\mathrm{se}}=\mathrm{A} \rho_{\mathrm{v}}+\mathrm{B} \rho_{\mathrm{h}}
$$

where $\rho_{\mathrm{v}}$ and $\rho_{\mathrm{h}}$ are the fraction of vertical and horizontal steel, respectively, and for:

$$
\begin{array}{lll}
\mathrm{h}_{\mathrm{w}} / \mathrm{l}_{\mathrm{w}} \leq 0.5 & \mathrm{~A}=1 & \mathrm{~B}=0 \\
0.5 \leq \mathrm{h}_{\mathrm{w}} / \mathrm{l}_{\mathrm{w}} \leq 1.5 & \mathrm{~A}=-\mathrm{h}_{\mathrm{w}} / \mathrm{l}_{\mathrm{w}}+1.5 & \mathrm{~B}=\mathrm{h}_{\mathrm{w}} / \mathrm{l}_{\mathrm{w}}-0.5 \\
1.5 \leq \mathrm{h}_{\mathrm{w}} / \mathrm{l}_{\mathrm{w}} & \mathrm{A}=0 & \mathrm{~B}=1
\end{array}
$$

EPRI (1991 [DIRS 161330], Appendix L, pp. L-3 and L-4) also shows that the logarithmic standard deviation, $\beta$, of data about this median capacity is about 0.20 . Thus, the 84 percent exceedance probability ultimate shear capacity, $\mathrm{v}_{\mathrm{u}}$, equation is:

$$
\mathrm{v}_{\mathrm{u}}=\phi \mathrm{v}_{\mathrm{n}}
$$

where $\phi=\mathrm{e}^{-\beta}=0.80$ is the required strength reduction factor.

Equation A-6 defines the high confidence shear strength capacity of a low-rise concrete shear wall if Code specified minimum values are used for $f_{\mathrm{c}}{ }^{\prime}$ and $\mathrm{f}_{\mathrm{y}}$ in Equation A-3. Additional details are given in EPRI (1991 [DIRS 161330], Appendix L). This approach can be used to estimate the high confidence strength capacity for other failure modes if adequate test data are available. 


\section{A-3. PERMISSIBLE DRIFT LIMITS FOR LOW RISE CONCRETE SHEAR WALLS}

Based on an extensive review of test data for shear walls subjected to cyclic loads, Duffey, et al., Shear Wall Ultimate Drift Limits (1994 [DIRS 161328]) established estimates of the shear drift capability of concrete shear walls.

Duffey, et al. (1994 [DIRS 161328], Figure 2.1) show that the drift limit corresponding to ultimate load capacity is insensitive to aspect ratio $\left(\mathrm{h}_{\mathrm{w}} / \mathrm{I}_{\mathrm{w}}\right)$ for aspect ratios less than about 1.0. For higher aspect ratios, the drift limit increases with increasing aspect ratios. Therefore, Duffey, et al. (1994 [DIRS 161328], p. 16) established drift limit recommendations for concrete shear walls with aspect ratios between 0.24 and 1.07. Extending these drift limits to higher aspect ratio walls is conservative.

Test data also show that the drift limits corresponding to ultimate load capacity for walls with aspect ratios less than 1.0 increase when large percentages of vertical reinforcing steel is present. Therefore, the results presented by Duffey, et al. (1994 [DIRS 161328], p. 16) are limited to walls with small percentages of vertical reinforcing steel ranging between 0.0 percent to 0.86 percent with a median ratio of about 0.5 percent. Therefore, the use of these drift limit results for walls with higher reinforcing steel percentages is conservative.

Even low-rise concrete shear walls with low steel percentages can drift about two percent of their story height before they will actually fail. However, under cyclic loading, their strength capacity will degrade on subsequent cycles when prior drifts exceed certain lesser limits. Therefore Duffey, et al. (1994 [DIRS 161328], Table 4.3) presented drift limits corresponding to retention of load capacity ranging from 100 percent to 50 percent of the original ultimate capacity for subsequent cycles. Duffey, et al. (1994 [DIRS 161328], Table 4.3 and Section 4.2) summarized the median drift limits, $\mathrm{DL}_{50 \%}$, and logarithmic standard deviations, $\beta$, on these drift limits as a function of ultimate load capacity retained during subsequent non-linear cycles. This information is repeated in Table A-2. The 95 percent confidence drift limits, DL95\%, are given in Table A-2 as computed from:

$$
\mathrm{DL}_{95 \%}=\mathrm{DL}_{50 \%} \mathrm{e}^{-1.645 \beta}
$$

where 1.645 is the standardized normal variant associated with the five percent exceedance probability (modified from Kennedy 2001 [DIRS 155940], p. 35).

The Limit State C drift limit of 0.4 percent for low-rise concrete shear walls corresponds to a drift at which there is about 95 percent confidence that the ultimate load capacity will be retained during subsequent load cycles (DOE-STD-1020-94 1994 [DIRS 161324], Section 2.3). Therefore, there is about 95 percent confidence that the wall will retain its full strength and will remain fully serviceable. Although not shown in Table A-2, test data indicate that cracks will remain small (DOE-STD-1020-94 1994 [DIRS 161324], Table C.2).

Similarly, the Limit State A drift limit of 0.75 percent for low-rise concrete shear walls corresponds to a drift at which there is about 95 percent confidence that about 50 percent of the ultimate load capacity will be retained, and about 50 percent confidence that 100 percent of the ultimate load capacity will be retained. This retained strength is sufficient to provide high 
confidence that collapse will be prevented. However, the structure might suffer significant damage and might not be repairable back to its original strength.

The Limit State B drift limit of 0.6 percent corresponds to a drift at which there is about 95 percent confidence that 80 percent of the ultimate load capacity will be retained. Test data show that crack widths might begin to become significant beyond this drift limit. These larger cracks could reduce the capacity of anchorage that anchors components to the wall.

\section{A-4. SUMMARY STATEMENTS ON APPROACH FOR BEYOND DESIGN BASIS EARTHQUAKE GROUND MOTION ANALYSES}

1. The BDBGM is established at the $1 \times 10^{-4} / \mathrm{yr}$ exceedance frequency for SSCs ITS designed to DBGM-2.

2. The strength capacities to be used in the analyses will either be the Code strength capacities (including Code-specified strength reduction factors $\phi$ ) or strength capacities established at about the 98 percent exceedance probability level when sufficient test data exist to estimate this strength capacity level.

3. Computed non-linear responses will be limited to Limit State C drift limits (less than 0.4 percent of the story height). These limits provide about 95 percent confidence that the structure will retain its original ultimate capacity, permanent distortions will be small, damage will be minimal, and the structure will remain serviceable.

This combination of strengths (summarized under Item 2) and non-linear drifts (limited to those in Item 3) leads to HCLPF for the structure to remain functional when subjected to the BDBGM. Some minor repairs may be required to maintain long-term functionality.

Table A-1. Structural Deformation Limits for Limit States

\begin{tabular}{|c|l|l|}
\hline Limit State & \multicolumn{1}{|c|}{ Structural Deformation Limit } & \multicolumn{1}{|c|}{ Amount of Damage } \\
\hline A & Large Permanent Distortion, Short of Collapse & Significant \\
\hline B & Moderate Permanent Distortion & Generally Repairable \\
\hline C & Limited Permanent Distortion & Minimal \\
\hline D & Essentially Elastic Behavior & None \\
\hline
\end{tabular}

Source: Developed for this report. 
Table A-2. Drift Limits For Low Rise Concrete Shear Walls as a Function of Percentage of Ultimate Load Capacity Retained During Cyclic Loading

\begin{tabular}{|c|c|c|c|}
\hline $\begin{array}{c}\text { Percentage of Ultimate } \\
\text { Load Retained }\end{array}$ & $\begin{array}{c}\text { Median Drift Limit } \\
\text { (DL50\%) }\end{array}$ & $\begin{array}{c}\text { Log. Std. } \\
\text { Deviation ( } \beta \text { ) }\end{array}$ & $\begin{array}{c}\text { 95\% Confidence } \\
\text { Drift Limit (DL95\%) }\end{array}$ \\
\hline $100 \%$ & $0.72 \%$ & 0.373 & $0.39 \%$ \\
\hline $90 \%$ & $1.00 \%$ & 0.437 & $0.49 \%$ \\
\hline $80 \%$ & $1.24 \%$ & 0.452 & $0.59 \%$ \\
\hline $70 \%$ & $1.48 \%$ & 0.464 & $0.69 \%$ \\
\hline $60 \%$ & $1.64 \%$ & 0.524 & $0.69 \%$ \\
\hline $50 \%$ & $1.84 \%$ & 0.566 & $0.73 \%$ \\
\hline
\end{tabular}

Source: Modified from Duffey, et al. (1994 [DIRS 161328], Table 4.3)

NOTE: Log. Std. = Logarithmic standard. 
APPENDIX B

DEVELOPMENT OF HCLPF SEISMIC MARGIN ESTIMATES 
INTENTIONALLY LEFT BLANK 


\section{APPENDIX B \\ DEVELOPMENT OF HCLPF SEISMIC MARGIN ESTIMATES}

\section{B-1 INTRODUCTION}

This appendix describes the methodology that will be followed to develop HCLPF estimates for SSCs ITS that are identified in seismically-initiated event sequences. The HCLPF estimates will be used to evaluate seismic margins and in the PCSA to assure that the preclosure performance objectives of 10 CFR 63.111 [DIRS 156605] are met.

In the early 1980s, the NRC formed an Expert Panel on Quantification of Seismic Margins to provide the NRC advice on how to define the seismic margin beyond the DBGM. The Panel's advice is presented in Budnitz, et. al. (1985 [DIRS 165660]). The Panel recommended that the seismic margin should conservatively be defined in terms of the HCLPF seismic capacity and stated (p. 2-1) that:

"This so-called HCLPF point can serve operationally as a conservative estimate of the actual earthquake size where the plant (or any component, structure, or system) has a small chance of being compromised."

The HCLPF seismic capacity is defined mathematically as the point on the seismic fragility curve corresponding to approximately 95 percent confidence of not exceeding about a five percent probability of failure. Alternately, Chen et al. (1991 [DIRS 162002]) states on page 7 that the HCLPF capacity can be approximated by the one percent probability of failure point on the composite (mean) fragility curve. In addition to these mathematical definitions, the Panel states on pages 3 and 2-2:

"The measure of margin adopted by the panel is a high-confidence, low probability-of-failure (HCLPF) capacity. This is a conservative representation of capacity and in simple terms corresponds to the earthquake level at which it is extremely unlikely that failure of the component will occur."

and states on page 5-2:

"There is a margin above the conservative capacity values selected by the Panel. The median capacity, which corresponds to the 50 percent probability of exceedance, is generally at least a factor of 2 greater than the HCLPF capacity. Thus, there is no proverbial "cliff" or sudden failure which is expected to occur immediately beyond the HCLPF capacity. From another perspective, the conservative capacities are close to the lower-bound cutoff values below which there is no significant likelihood of failure. Although lower-bound capacity values have not been rigorously established, it is the belief of many engineers that lower bound capacity values do exist in the absence of major design and construction errors."

In summary, the HCLPF capacity represents a conservative seismic capacity estimate below which failure is very unlikely. 
Seismically-initiated event sequences identified in the PCSA as being capable of resulting in significant releases will be defined. These seismically-initiated event sequences will be defined by simplified fault and event tree models to identify the SSCs that contribute to the event sequence when they fail to perform their function. HCLPF seismic capacity estimates will be made for each of the SSCs identified in the seismically-initiated event sequences capable of resulting in significant releases. The HCLPF seismic margin for each of these SSCs will be computed as the ratio of the HCLPF seismic capacity to the $1 \times 10^{-4} / \mathrm{yr}$ exceedance frequency ground motion level and will be reported. To be acceptable, the HCLPF seismic margin should be greater than 1.0 and a target minimum value of 1.10 is deemed acceptable for these SSCs. In this way it will be demonstrated that there is less than a one percent chance of a significant release at the $1 \times 10^{-4} / \mathrm{yr}$ exceedance frequency ground motion level.

Where it can be demonstrated by simplified bounding analyses that the HCLPF seismic margin for an SSC exceeds 1.50, no HCLPF capacity will be computed and it will be reported that the HCLPF seismic margin exceeds 1.50 as opposed to reporting a specific value.

\section{B-2. ESTABLISHING LIMITS ON PERMISSIBLE DAMAGE}

Prior to development of a HCLPF capacity estimate for each SSC, it will be necessary to specify a clear definition of what constitutes unacceptable damage for each specific SSC in the event sequence. Table A-1 in Appendix A divides the definition of damage into four candidate limit states. In general, damage will be defined by one of these four limit states.

Limit State A is basically a local collapse prevention limit state that will be specified when continued functionality is not an issue and it is only necessary to prevent gross failure. Limit State C corresponds to continued serviceability and functionality for most SSCs, and structures will continue to serve as a reasonable confinement barrier at Limit State C. Limit State B is midway between Limit States A and C. Active components may or may not continue to function at Limit State B depending on their function. Anchorage of components attached to walls and roofs of structures may be compromised if the structure deforms beyond Limit State B. Therefore, if critical components, which must remain functional, are mounted on walls and roofs of a structure, Limit State B will be specified for the structure. Limit State D is essentially elastic behavior. It will be specified for certain active rotating components, such as pumps, where inelastic deformations might result in loss of function. However, in general, Limit State D is not appropriate for HCLPF estimates for structures and passive components. The appropriate limit state will be jointly selected for each SSC in each event sequence by system safety analysts and structural evaluation analysts.

\section{B-3. DEVELOPMENT OF HCLPF CAPACITIES and SEISMIC FRAGILITIES}

A HCLPF seismic capacity estimate, $\mathrm{C}_{\mathrm{HCLPF}}$, is deterministically computed using the Conservative-Deterministic-Failure-Margin (CDFM) methodology (EPRI 1991 [DIRS 161330], pp. 2-45 to 2-56) to obtain $\mathrm{C}_{\mathrm{CDFM}}$. Alternatively, the capacity evaluation methodology (DOE-STD-1020-94 1994 [DIRS 161324], Section C.5; Kennedy and Short 1994 [DIRS 161326], Section 4.2) can be used to define C CDFM. Kennedy (2001 [DIRS 155940], Sections 3 and 5) shows that the HCLPF capacity computed by the CDFM method closely 
approximates the conditional one percent failure probability capacity, $\mathrm{C}_{1 \%}$, point on the composite (mean) seismic fragility curve:

$$
\mathrm{C}_{\mathrm{HCLPF}} \approx \mathrm{C}_{\mathrm{CDFM}} \approx \mathrm{C}_{1 \%}
$$

so that these capacity definitions may be used interchangeably. The CDFM method is the most commonly used method for estimating HCLPF capacities and has been accepted by the NRC (Chen et al. 1991 [DIRS 162002]) for estimating HCLPF capacities.

\section{B-4. EVALUATION OF CDFM CAPACITIES}

The CDFM capacity of any SSC can be estimated from:

$$
\mathrm{C}_{\mathrm{CDFM}}=\mathrm{F}_{\mathrm{S}} * \mathrm{~F}_{\mu} * \mathrm{DBGM}
$$

where DBGM is the design basis ground motion for which the SSC has been designed, $\mathrm{F}_{\mathrm{S}}$ is a computed strength margin factor, and $\mathrm{F}_{\mu}$ is an inelastic energy absorption factor (derived from EPRI 1991 [DIRS 161330], p. 2-45 to 2-55).

\section{B-4.1 Strength Margin Factor}

The strength margin factor is given by:

$$
\mathrm{F}_{\mathrm{S}}=\frac{\mathrm{F}_{\mathrm{C}} \mathrm{C}_{\mathrm{C}}-\mathrm{D}_{\mathrm{NS}}}{\mathrm{D}_{\mathrm{S}}}
$$

where $C_{C}$ is the capacity computed using Code capacity acceptance criteria (including Code specified strength reduction factors $\phi$ ), $\mathrm{D}_{\mathrm{NS}}$ is the expected concurrent non-seismic demand, $\mathrm{D}_{\mathrm{S}}$ is the conservatively estimated seismic demand computed for the DBGM input, and $\mathrm{F}_{\mathrm{C}}$ is a capacity increase factor (based on EPRI 1991 [DIRS 161330], Equation 2-6 and Kennedy 2001 [DIRS 155940], Appendix A). The seismic demand, $\mathrm{D}_{\mathrm{S}}$, will be computed in accordance with the requirements of ASCE 4-98 (ASCE 4-98 2000 [DIRS 159618], Section 3.1.1.2) to provide a slightly conservative seismic demand estimate. The capacity increase factor, $\mathrm{F}_{\mathrm{C}}$, is given by:

$$
\mathrm{F}_{\mathrm{C}}=\frac{\mathrm{C}_{98 \%}}{\mathrm{C}_{\mathrm{C}}}
$$

where $\mathrm{C}_{98 \%}$ is the estimated 98 percent exceedance probability capacity.

Appendix A, Section A.2, specifies the approach that will be used to estimate C $_{98 \%}$ for the shear strength of low-rise concrete shear walls. This approach was taken from EPRI (1991 [DIRS 161330]). A number of examples for estimating $C_{98 \%}$ for other SSCs are also given in EPRI (1991 [DIRS 161330], (e.g., Appendices L and M), and this guidance will be followed. When data are inadequate to estimate $\mathrm{C}_{98 \%}$ or for the sake of simplicity, $\mathrm{F}_{\mathrm{C}}$ will often be taken as 1.0 .

\section{B-4.2 Inelastic Energy Absorption Factor}


In the CDFM Method (Kennedy 2001 [DIRS 155940], Section A.2.4; EPRI 1991 [DIRS 161330], Table 2-5), the inelastic energy absorption factor, $F_{\mu}$, is to be estimated at the 95 percent exceedance probability. Conservative generic estimates of 95 percent exceedance probability $F_{\mu}$ for structures are given in DOE-STD-1020-94 (1994 [DIRS 161324], Table 2-4) for Limit State C. These $F_{\mu}$ values will be appropriately increased for Limit States A and B. For example, the $F_{\mu}=1.5$ value given in DOE-STD-1020-94 (1994 [DIRS 161324], Table 2-4) for low-rise (shear controlled) concrete shear wall structures is a conservative generic estimate reasonably corresponding to an allowable story drift limit of 0.4 percent appropriate for Limit State C. Allowable drift limits are higher for Limit States A (0.75 percent) and B (0.6 percent). For low-rise shear walls, conservative generic inelastic energy absorption factors, $\mathrm{F}_{\mu}$, for Limit States $A$ and $B$ are estimated by increasing the Limit State $C$ factor, $F_{\mu}$, by slightly less than the square root of the ratio of allowable drift limits. The resulting $F_{\mu}$ values for (reinforced concrete shear wall - in plane) low-rise shear walls are 2.0, 1.75, and 1.5 for Limit States A, B, and C, respectively (modified from DOE-STD-1020-94 1994 [DIRS 161324], Table 2-4) ${ }^{3}$.

\section{B-5. REFINEMENT OF CDFM CAPACITY ESTIMATES}

As outlined in Appendix A, analyses will be conducted for structures identified in the PCSA as being ITS if the PCSA indicates that their postulated failure could lead to dose consequences exceeding the preclosure performance objectives of 10 CFR 63.111 [DIRS 156605]. These analyses will be performed for a BDBGM established at the $1 \times 10^{-4} / \mathrm{yr}$ exceedance frequency. If the computed seismic demand/capacity ratio $\left(D_{S} / C_{S}\right)$ exceeds the Limit State $C$ permissible $F_{\mu}$ for the BDBGM input, then a non-linear evaluation is required in Step 4 of Appendix A. After completion of the BDBGM non-linear evaluation, the same non-linear model of the structure can be used to refine the CDFM Capacity estimate. The refined CDFM Capacity estimate is expected to be higher than that estimated by the approach presented in Section B-4.

An improved estimate of $\mathrm{C}_{\mathrm{CDFM}}$ is obtained by scaling the BDBGM input upward and repeating the non-linear evaluation until the structural deformation limits given in Appendix A for the appropriate limit state are reached. The improved estimate of $\mathrm{C}_{\mathrm{CDFM}}$ equals the ground motion at which these deformation limits are reached. This improved estimate of $\mathrm{C}_{\mathrm{CDFM}}$ will be performed for any structure that has to be evaluated by Step 4 of Appendix A. Improved estimates might be made for additional structures by performing similar non-linear analyses for ground motion higher than the BDBGM.

\footnotetext{
${ }^{3}$ The American Society of Civil Engineers is expected to issue a standard on seismic design criteria for SSCs in nuclear facilities. The standard will provide allowable drift and inelastic rotation limits, and generic conservative $\mathrm{F}_{\mu}$ values for a variety of structural systems and components for Limit States A, B, and C. The drift limits presented in Appendix $\mathrm{A}$, and the $\mathrm{F}_{\mu}$ values presented here, are consistent with those expected in the forthcoming ASCE standard.
} 